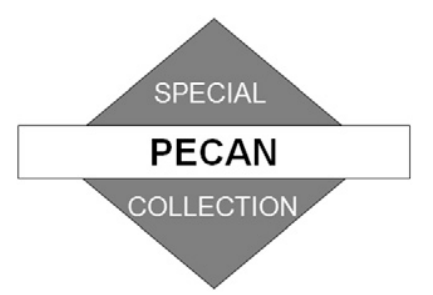

\title{
Multicase Assessment of the Impacts of Horizontal and Vertical Grid Spacing, and Turbulence Closure Model, on Subkilometer-Scale Simulations of Atmospheric Bores during PECAN
}

\author{
AARON JOHNSON AND XUGUANG WANG \\ School of Meteorology, University of Oklahoma, Norman, Oklahoma
}

(Manuscript received 11 September 2018, in final form 5 February 2019)

\begin{abstract}
Four case studies from the Plains Elevated Convection at Night (PECAN) field experiment are used to investigate the impacts of horizontal and vertical resolution, and vertical mixing parameterization, on predictions of bore structure and upscale impacts of bores on their mesoscale environment. The reduction of environmental convective inhibition (CIN) created by the bore is particularly emphasized. Simulations are run with horizontal grid spacings ranging from 250 to $1000 \mathrm{~m}$, as well as $50 \mathrm{~m}$ for one case study, different vertical level configurations, and different closure models for the vertical turbulent mixing at 250-m horizontal resolution. The 11 July case study was evaluated in greatest detail because it was the best observed case and has been the focus of a previous study. For this case, it is found that 250-m grid spacing improves upon 1-km grid spacing, LES configuration provides further improvement, and enhanced low-level vertical resolution also provides further improvement in terms of qualitative agreement between simulated and observed bore structure. Reducing LES grid spacing further to $50 \mathrm{~m}$ provided very little additional advantage. Only the LES experiments properly resolved the upscale influence of reduced low-level CIN. Expanding on the 11 July case study, three other cases from PECAN with diverse observed bore structures were also evaluated. Similar to the 11 July case, enhancing the horizontal and vertical grid spacings, and using the LES closure model for vertical turbulent mixing, all contributed to improved simulations of both the bores themselves and the largerscale modification of CIN to varying degrees on different cases.
\end{abstract}

\section{Introduction}

Atmospheric bores are commonly observed in the nocturnal convective environment in the Great Plains (Haghi et al. 2017). This is because the stable boundary layer and low-level jet often provide a suitable wave duct, while convectively generated cold pools frequently provide an obstacle to this stable and ducted low-level flow (Rottman and Simpson 1989; Johnson et al. 2018). Several studies have demonstrated the importance of bores in both the initiation and maintenance of deep convection when a low-level stable layer (i.e., the nocturnal boundary layer) is present (e.g., Koch et al. 1991; Karyampudi et al. 1995; Knupp 2006; Parker 2008; Coleman and Knupp 2011; Parsons et al. 2019). The mechanisms of bore influence on convection initiation include the lifting of parcels to

Corresponding author: Dr. Aaron Johnson, ajohns14@ou.edu their level of free convection to initiate new cells, and the reduction of convective inhibition (CIN) which reduces the lifting by the parent density current that is needed to initiate new cells (Haghi et al. 2019). The influence on convective maintenance also results from a reduction in CIN resulting from the bore lifting (Parker 2008; Haghi et al. 2019). Better understanding and prediction of bores is needed to improve upon the relatively low skill of precipitation forecasts during the warm season (e.g., Davis et al. 2003; Surcel et al. 2010), since most of the warm season precipitation occurs at night in the Great Plains (Wallace 1975).

The Plains Elevated Convection at Night (PECAN) field experiment took place in 2015 with the purpose of collecting comprehensive and targeted observations of bores and other phenomena related to nocturnal convection (Geerts et al. 2017). One use of these unprecedented observations is the ability to validate the details of model simulated bores to better understand the 
sensitivities and sources of error in numerical weather prediction (NWP) involving bores. For example, Johnson et al. (2018) used data from the 11 July 2015 PECAN intensive observing period (IOP) to investigate the role of model physics configurations in the performance of model predictions of the observed bore, but did not consider the influence of model resolution. Since the cold pool strength and depth are strongly sensitive to the microphysics parameterization, it was shown that this sensitivity carries over to the bore prediction with the WRF single-moment 6-class microphysics scheme (WSM6; Hong and Lim 2006) providing the best prediction in this case (Johnson et al. 2018). It was also shown that the boundary layer parameterization affects not only the characteristics of the prebore environment, but also the turbulent characteristics and structure of the bore itself (Johnson et al. 2018), with the MYNN scheme being particularly poorly suited for simulating this bore. An important aspect of model uncertainty that was not examined in Johnson et al. (2018) is the model resolution.

A horizontal grid spacing of $1-4 \mathrm{~km}$ is sufficient to permit deep convection and related phenomena, but may not actually resolve such phenomena accurately (e.g., Bryan et al. 2003; Weisman et al. 2008). However, the mesoscale characteristics of such convection are better represented at these convection-permitting resolutions than at slightly coarser resolutions that require convective parameterization (e.g., Weisman et al. 2008; Clark et al. 2010a,b; Iyer et al. 2016). Bores occur on scales even smaller than the convective systems that they can interact with. The evolution of a bore typically depends on the ducting of gravity waves with horizontal wavelengths of $1-10 \mathrm{~km}$ and vertical wavelengths on the order of $\sim 1 \mathrm{~km}$. Furthermore, bores are known to modify their environment (e.g., Karyampudi et al. 1995; Koch et al. 2008a; Parsons et al. 2019) and one of the ways that they are known to do this is through turbulent mixing processes that occur on scales less than $1 \mathrm{~km}$ (Koch et al. 2008a). The vertical grid spacing is also hypothesized to be important for bore simulations because of the role of vertical gradients of wind shear and stability in wave ducting, and because of the role of vertical turbulent mixing. While previously published bore simulations have used horizontal grid spacings ranging from 0.7 to $4 \mathrm{~km}$ (e.g., Koch et al. 2008a; Martin and Johnson 2008; Hartung et al. 2010; Blake et al. 2017; Osborne and Lapworth 2017; Johnson et al. 2018), there has not been a systematic study of the necessary and sufficient horizontal and vertical model grid spacing requirements for accurately simulating not only bore evolution, but also the aggregate upscale impacts of bores on the mesoscale environment via mean layer lifting and turbulent mixing.

When turbulent eddies occur on similar spatial scales as the model grid spacing (i.e., $\sim 100-1000 \mathrm{~m}$ in convective boundary layers), the largest spatial scales in the inertial subrange are neither fully resolved on the model grid, nor fully subgrid (Wyngaard 2004; Verrelle et al. 2015). This complicates the choice of a closure model for vertical mixing by turbulence. Neither a planetary boundary layer (PBL) parameterization as the closure model [denoted herein as convection permitting model (CPM)] nor a subgrid-scale closure model like the Smagorinsky (1963) scheme are quite justified (Verrelle et al. 2015). Since the Smagorinsky closure presumes the largest turbulent eddies to be resolvable, we refer to this as a large-eddy simulation (LES) framework in this study. Some studies have used the LES framework on subkilometer scales (e.g., Bryan et al. 2003; Potvin and Flora 2015; Morrison et al. 2015; Cioni and Hohenegger 2017; Hanley et al. 2015; Heath et al. 2017), while others have had success with the CPM approach (e.g., Shin and Dudhia 2016; Verrelle et al. 2015; Ito et al. 2017). The LES and CPM frameworks have also been directly compared at the same grid spacing (200 and $333 \mathrm{~m}$, respectively) in Fiori et al. (2010) and Green and Zhang (2015) for an idealized supercell and a tropical cyclone simulation, respectively. Although sensitivities were demonstrated, a generally optimal framework for these phenomena was not determined. We acknowledge that it could be argued that the term "LES" specifies whether or not the grid spacing can resolve turbulent eddies, regardless of the turbulence closure model. For a model simulation covering thousands of kilometers in the horizontal, tens of kilometers in the vertical, and several hours of time, it could also be argued that specifying the entire simulation as LES or not is also an overgeneralization. In this paper we leave this debate open and simply use the monikers LES and CPM to refer specifically to the flow regime that the corresponding vertical turbulence closure model is typically applied for, following the similar terminology of Rai et al. (2019).

Since there is no consensus on whether the CPM or LES framework is better suited for predicting nocturnal continental convection and the accompanying atmospheric bores at $\sim 250$-m grid spacing, both approaches are compared at the same 250 -m horizontal grid spacing in this study. Furthermore, the CPM at $250-\mathrm{m}$ grid spacing is compared to a more operationally tractable 1-km grid spacing CPM, and the LES at 250-m grid spacing is compared to a much finer 50-m grid spacing LES. In addition to these experiments on the horizontal grid spacing, experiments on the spacing of vertical 
levels are also conducted as described in greater detail below (section 3). The Advanced Research version of the Weather Research and Forecasting (WRF) Model (ARW; Skamarock et al. 2005) is adopted for not only the CPMs, but also the LESs, which allows for full complexity physics and realistic surface processes. Impacts are evaluated in terms of qualitative appearance of the simulated bores, objectively quantified bore height and evolution of the vertical profile of CIN during bore passage.

The structure of this paper is as follows. The PECAN bore observations that are used for model validations are presented in section 2, and the details of the experiment configurations are explained in section 3 . Section 4 presents the results for the 11 July case study while section 5 extends a limited subset of the experiments to the other cases in order to determine how sensitive the results are to the specifics of the one event. The conclusions are summarized and discussed in section 6 .

\section{Overview of observed bore events}

A bore is characterized by a step-like increase in the depth of a stable fluid such as the nocturnal boundary layer. A bore is distinguished from other features that may create a similar increase in depth, such as a cold pool or cold front, by the lack of significant near-surface cooling. The bore events used for this multicase assessment were selected because of the presence of observations for model validation and data assimilation beyond what are typically available operationally. In particular, at least one time-height cross section through each of the bores is available from an Atmospheric Emitted Radiance Interferometers (AERI; Turner and Löhnert 2014; Turner 2016, 2017). In short, the AERI instrument uses downwelling infrared radiation at wavelengths ranging from 3.3 to $19.2 \mu \mathrm{m}$ to retrieve the vertical profile of temperature and water vapor in the lowest $\sim 3 \mathrm{~km}$ of the atmosphere. While it can sometimes be challenging to distinguish bores from other features using only reflectivity or surface observations (e.g., Haghi et al. 2017), the AERI retrievals allow us to unambiguously identify the features in this study as bores by revealing the step-like increase in layer depth that is characteristic of bores.

The 11 July 2015 bore was particularly well observed and many of these observations are described in detail in Johnson et al. (2018). The base level reflectivity shows at least two parallel southwardpropagating fine line features corresponding to the undular bore (red ellipse in Fig. 1a). The leading wave can be followed continuously northeastward and northward to just east of the KUEX radar location

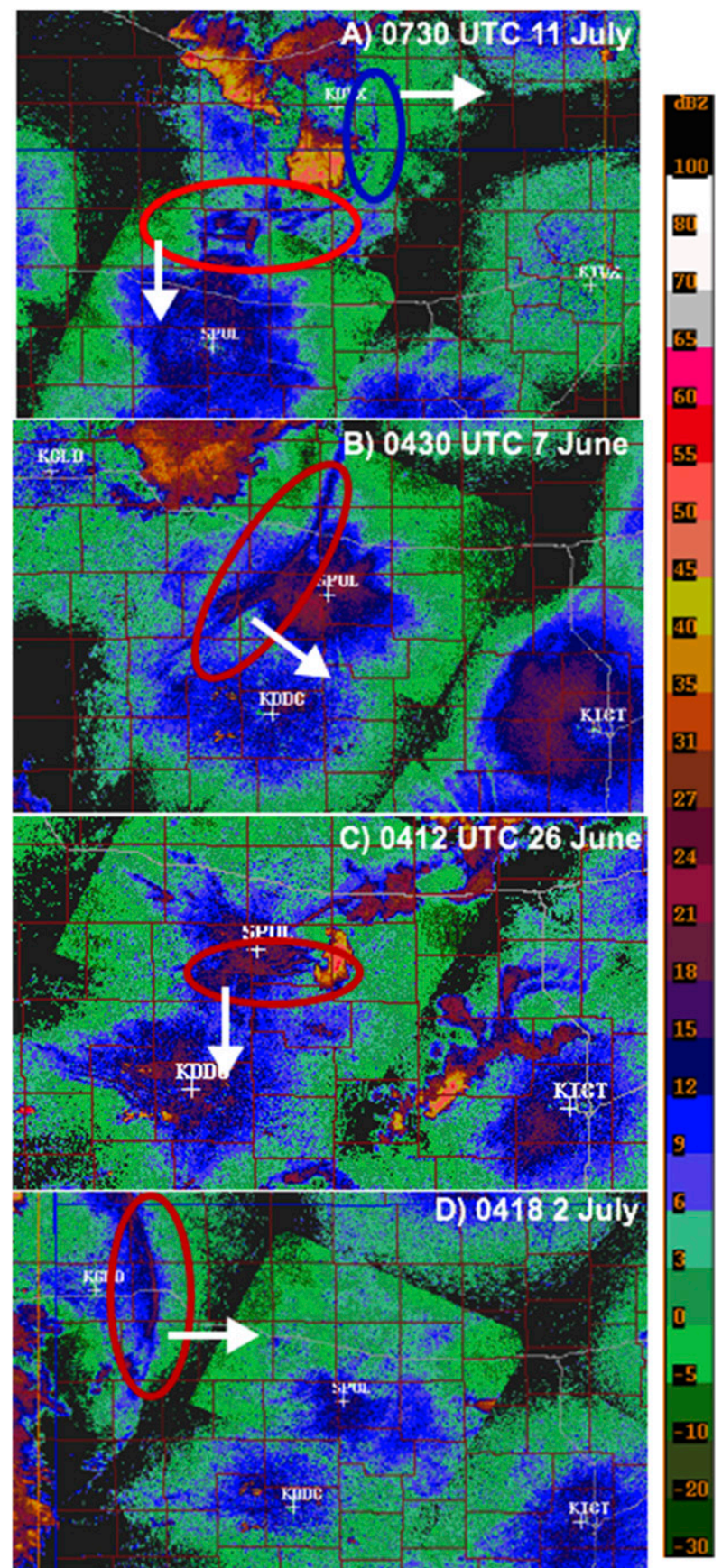

FIG. 1. Base-level-reflectivity mosaic product from the PECAN Field Catalog at (a) 0730 UTC 11 Jul, (b) 0430 UTC 7 Jun, (c) 0412 UTC 26 Jun, and (d) 0418 UTC 2 Jul 2015. Ellipses indicate the bores referenced in the text. White arrows indicate direction of bore propagation.

(blue ellipse in Fig. 1a). This is an indication of an eastward-propagating section of the bore, which was also confirmed by mobile sounding teams deployed during the IOP (not shown). A total of eight thermodynamic transects of the bore from both ground-based 

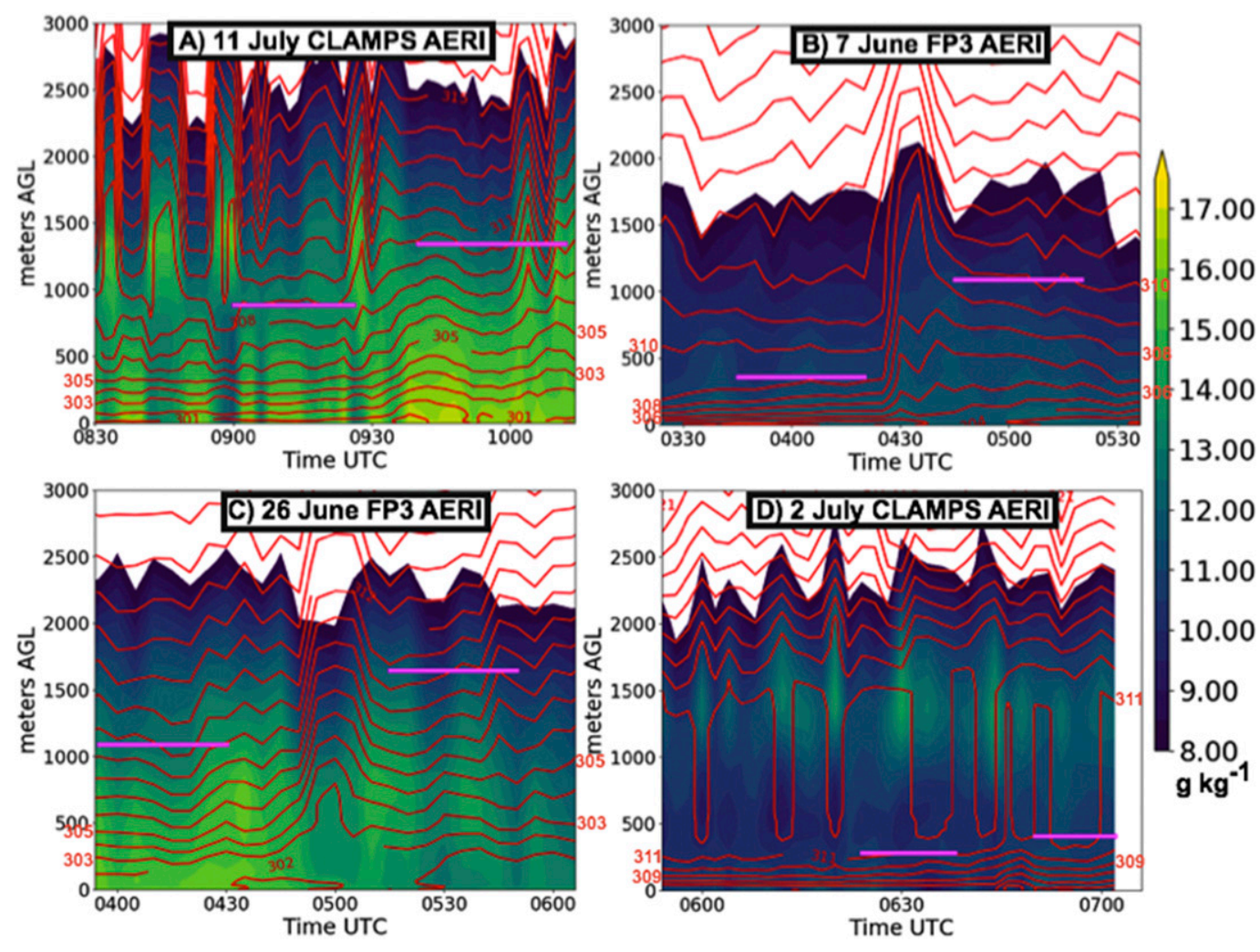

FIG. 2. Cross sections of water vapor mixing ratio (shading) and potential temperature for (a) 11 Jul bore from CLAMPS AERI, (b) 7 Jun bore from FP3 AERI, (c) 26 Jun bore from FP3 AERI, and (d) 2 Jul bore A from MP1 CLAMPS AERI. Horizontal lines in this and other cross sections indicate the prebore and postbore top of the nocturnal stable layer, following Johnson et al. (2018). Red labels have been added to the endpoints of some potential temperature contours to enhance readability.

AERI and aircraft-based lidar retrievals were used in Johnson et al. (2018) to identify the bore amplitude, defined as the unitless ratio of postbore stable layer depth over prebore stable layer depth, as 1.4 , with minimal variability at different times during the event (e.g., Fig. 2a). Johnson et al. (2018) also presented evidence of additional lofting of moisture above the bore, which was speculated to be a result of turbulent mixing in the bore. Qualitatively, the low-level vertical motion observed by the Mobile PECAN Integrated Sounding Array (PISA) 2 lidar (Fig. 3) indicates that the flow transitioned from primarily laminar to primarily turbulent at low levels after about one and a half wavelengths of bore undulation. This is reflected in Fig. 3 by the smooth appearance of perturbations in the vertical velocity field associated with the wave before $\sim 0830$ UTC, compared to the noisier appearance of the vertical velocities after $\sim 0830$ UTC.

In addition to the 11 July 2015 bore, three other bores from different nights are also considered in this study. The observed structure of these bores is quite diverse. The second bore considered in this study is from 7 June 2015 (Fig. 1b). Unlike the undular bore from the 11 July case, the 7 June bore is characterized by a single high-amplitude wave, followed by

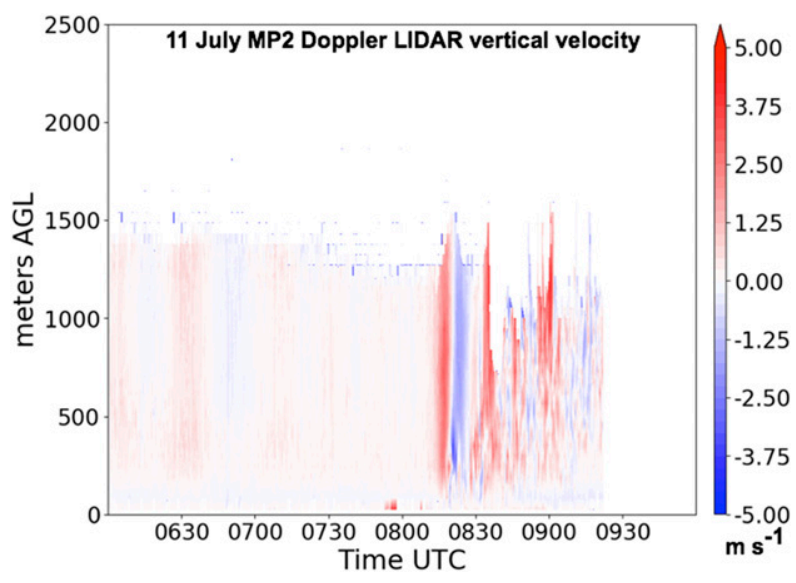

FIG. 3. Vertical velocity retrieved from the Mobile PISA 2 lidar (Knupp and Wade 2016) during bore passage at $\sim 0800-0900$ UTC $11 \mathrm{Jul}$ 2015. Adapted from Fig. 4b of Johnson et al. (2018). 
TABLE 1. Bore amplitudes, defined as the ratio of postbore stable layer depth over prebore stable layer depth, for the observed bores shown in Fig. 2, calculated following the method described in Johnson et al. (2018)

\begin{tabular}{lcc}
\hline \hline Bore event & Observing AERI & Amplitude \\
\hline 11 Jul 2015 & CLAMPS & 1.39 \\
7 Jun 2015 & FP3 & 2.76 \\
26 Jun 2015 & FP3 & 1.49 \\
2 Jul 2015 & CLAMPS & 1.44 \\
\hline
\end{tabular}

the expected quasi-permanent increase in the height of the nocturnal stable boundary layer (Fig. 2b). The third bore considered in this study is from 26 June 2015 (Fig. 1c). This bore was characterized by a leading lowamplitude wave that passed over the FP3 AERI at $\sim 0430$ UTC followed by a much larger amplitude second wave that reached the same location at $\sim 0500$ UTC (Fig. 2c). The fourth bore from 2 July 2015 (Fig. 1d) was characterized by a well-mixed residual layer above $\sim 500 \mathrm{~m}$ that trapped the bore below this level (Fig. 2d).
Since the 11 July case has already been well studied and understood by the authors in Johnson et al. (2018), it is used for a more detailed investigation while the other bores are used to test the robustness of key results over a variety of bores. The observed amplitudes of these bores are also summarized in Table 1.

\section{Experimental setup}

Initial conditions for the forecasts in this study are obtained following the Gridpoint Statistical Interpolation (GSI)-based ensemble Kalman filter (EnKF) system described in Johnson et al. (2018). In short, surface and upper air observations from the operational National Centers for Environmental Prediction (NCEP) data stream are assimilated on the outermost $12-\mathrm{km}$ domain every $3 \mathrm{~h}$, followed by assimilation of NEXRAD radar observations, together with the North American Mesoscale Forecast System (NAM) Data Assimilation System (NDAS) observations on the 1-km domain (Fig. 4) every $10 \mathrm{~min}$. The extension of the GSI EnKF system to the assimilation of the convective-scale radar observations

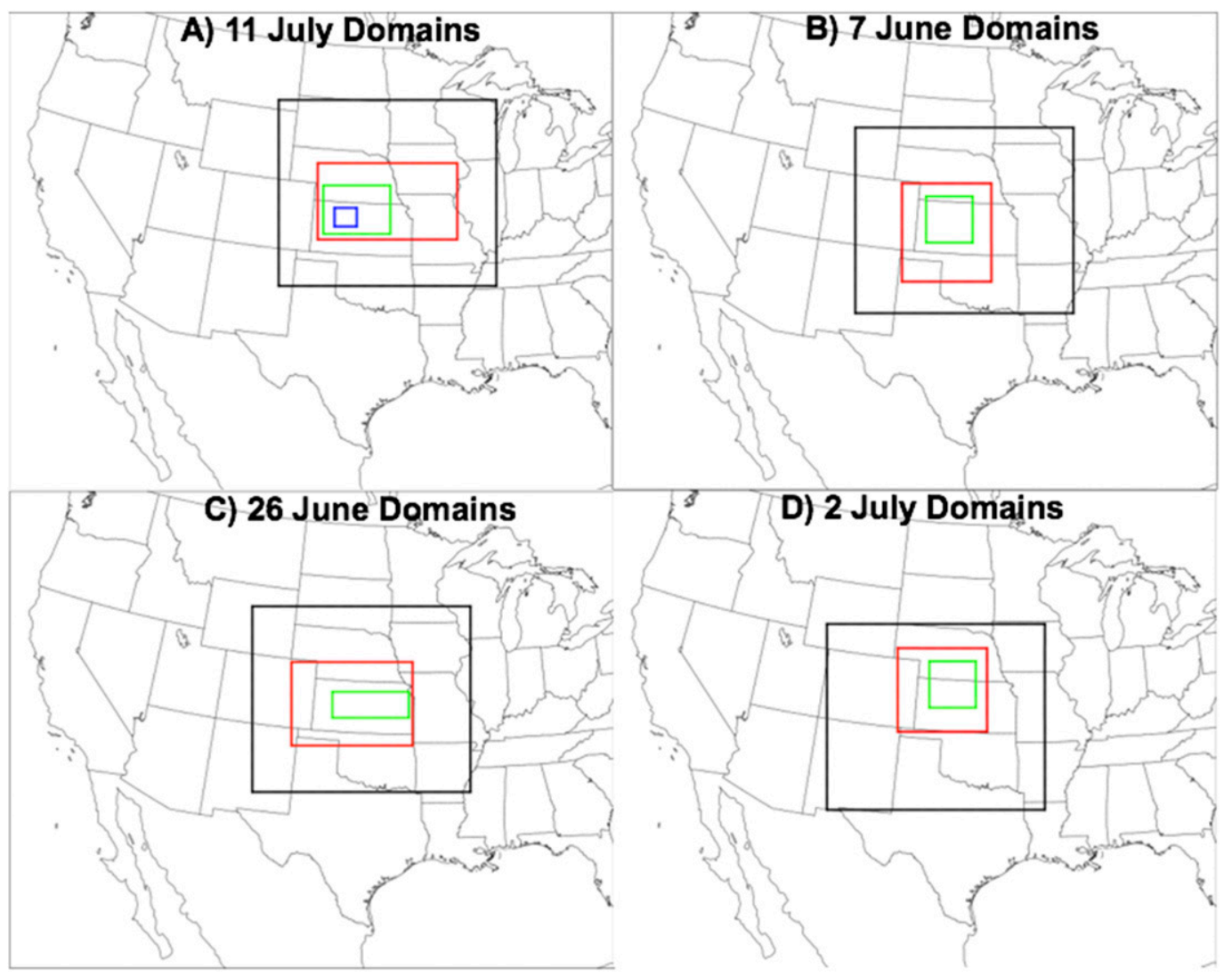

FIG. 4. Location of WRF nested domains used in this study for the (a) $11 \mathrm{Jul}$, (b) $7 \mathrm{Jun}$, (c) $26 \mathrm{Jun}$, (d) and 2 Jul bore events. The outermost domain has $12-\mathrm{km}$ grid spacing, the black box indicates the domain with $4-\mathrm{km}$ grid spacing, the red box indicates the domain with 1-km grid spacing, the green box indicates the domain with $250-\mathrm{m}$ grid spacing, and in (a) only the blue box indicates the domain with 50-m grid spacing. 
A) WRF default 50 levels (CTL)

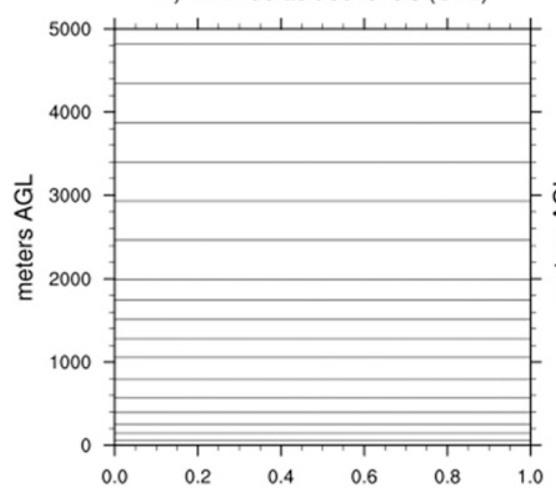

B) Enhance resolution evenly (NZEVEN)

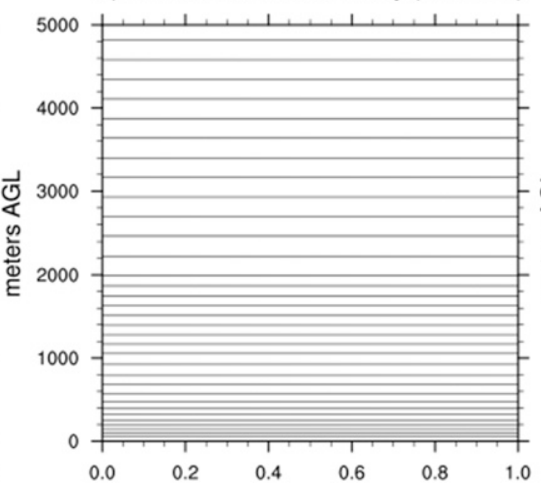

C) Enhance low-level resolution (NZLOW)

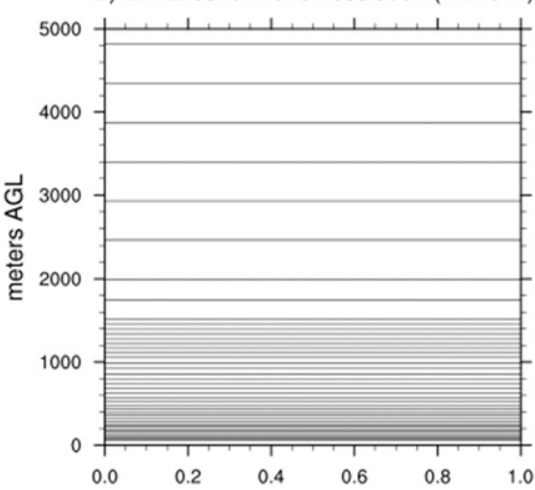

FIG. 5. Distribution of vertical levels in the lowest $5 \mathrm{~km} \mathrm{AGL}$ at a grid point at sea level for the (a) CTL, (b) NZEVEN, and (c) NZLOW experiments.

is described in Johnson et al. (2015), Johnson and Wang (2017), Johnson et al. (2017), and Wang and Wang (2017). The ensemble mean analysis on the 1-km domain is used to initialize the deterministic forecasts evaluated in this study. The forecast model is version 3.8 of the WRF ARW. All forecasts use the WSM6 (Hong and Lim 2006) microphysics scheme, Noah (Ek et al. 2003) land surface model, and Dudhia (1993) shortwave and RRTM (Mlawer et al. 1997) longwave radiation schemes. Forecasts that use a boundary layer parameterization use the Mellor-Yamada-Janjić (MYJ; Janjić 1994) scheme while the forecasts with the LES closure model use the Smagorinsky (1963) scheme to parameterize vertical turbulent mixing. All simulations use the Smagorinsky scheme to parameterize horizontal turbulent mixing.

The impacts of horizontal grid spacing and turbulent mixing are investigated using CPM simulations at $1-\mathrm{km}$ (red boxes in Fig. 4) and 250-m (green boxes in Fig. 4) horizontal grid spacings, and LES at 250-m (green boxes in Fig. 4) and 50-m (blue boxes in Fig. 4) horizontal grid spacings. The impacts of vertical resolution are investigated by running each of these forecasts with the same 50-level, WRF default stretched vertical grid as used during data assimilation (Fig. 5a), a 99-level default stretched vertical grid that enhances the vertical grid spacing evenly throughout the model depth (NZEVEN; Fig. 5b), and a manual modification of the default grid that decreases the vertical grid spacing by a factor of 4 below $\sim 1500 \mathrm{~m}$ AGL, resulting in 74 total levels (NZLOW; Fig. 5c). The analysis grid is interpolated to these additional vertical levels using the WRF.vinterp utility. All experiments are initialized at 0300 UTC, except for the 2 July experiment, which is initialized at 0200 UTC because the bore formed a little earlier in this case. The focus of this study is on the bores simulated at the 4-h lead time. This time is chosen as a compromise between the 11 July bore, which was observed $\sim 1-3 \mathrm{~h}$ after 0700 UTC, and the 7 June and 26 June bores, which were observed $\sim 1-3 \mathrm{~h}$ before 0700 UTC. It is desirable to evaluate the differences among the experiments at the same forecast lead time for all cases because the differences tend to grow with time, and we are interested in the differences in the experiment sensitivities resulting from the different meteorological conditions rather than the different forecast lead times. The one exception to this focus is the 26 June case. As a result of the widespread convection in this case, the bore must be evaluated at 0500 UTC (2-h lead time) before the bore interacts with a convective outflow to the south in the simulations. This lead time difference is taken into consideration when interpreting the results.

TABLE 2. Experiments for 11 Jul case with different vertical level distributions (see also Fig. 5), horizontal grid spacing, and vertical mixing parameterization [convection permitting model (CPM) with Mellor-Yamada-Janjić (MYJ) boundary layer parameterization, or large-eddy simulation (LES) with Smagorinsky vertical mixing parameterization].

\begin{tabular}{lccl}
\hline \hline \multicolumn{1}{c}{ Experiment } & $\begin{array}{c}\text { No. of } \\
\text { vertical } \\
\text { levels }\end{array}$ & $\begin{array}{c}\text { Horizontal } \\
\text { spacing } \\
(\mathrm{m})\end{array}$ & \multicolumn{1}{c}{$\begin{array}{c}\text { Vertical } \\
\text { mixing }\end{array}$} \\
\hline CPM_1km & 50 & 1000 & MYJ \\
CPM_250m & 50 & 250 & MYJ \\
LES_250m & 50 & 250 & Smagorinsky \\
LES_50m & 50 & 50 & Smagorinsky \\
CPM_1km_NZEVEN & 97 & 1000 & MYJ \\
CPM_250m_NZEVEN & 97 & 250 & MYJ \\
LES_250m_NZEVEN & 97 & 250 & Smagorinsky \\
LES_50m_NZEVEN & 97 & 50 & Smagorinsky \\
CPM_1km_NZLOW & 74 & 1000 & MYJ \\
CPM_250m_NZLOW & 74 & 250 & MYJ \\
LES_250m_NZLOW & 74 & 250 & Smagorinsky \\
LES_50m_NZLOW & 74 & 50 & Smagorinsky \\
\hline
\end{tabular}


TABLE 3. Experiments for the other cases besides the 11 Jul case.

\begin{tabular}{lccl}
\hline \hline \multicolumn{1}{c}{ Experiment } & $\begin{array}{c}\text { No. of } \\
\text { vertical } \\
\text { levels }\end{array}$ & $\begin{array}{c}\text { Horizontal } \\
\text { spacing } \\
(\mathrm{m})\end{array}$ & $\begin{array}{c}\text { Vertical } \\
\text { mixing }\end{array}$ \\
\hline CPM_1km & 50 & 1000 & MYJ \\
CPM_250m & 50 & 250 & MYJ \\
LES_250m & 50 & 250 & Smagorinsky \\
CPM_1km_NZLOW & 74 & 1000 & MYJ \\
CPM_250m_NZLOW & 74 & 250 & MYJ \\
LES_250m_NZLOW & 74 & 250 & Smagorinsky
\end{tabular}

The main difference between the CPM and LES framework is the parameterization of vertical turbulent mixing. In the CPM framework the boundary layer parameterization determines the mean turbulent flux, $-\overline{\left(w^{\prime} \varphi^{\prime}\right)}$, as follows:

$$
-\overline{\left(w^{\prime} \varphi^{\prime}\right)}=K_{\varphi} \frac{\partial \bar{\varphi}}{\partial z} .
$$

In Eq. (1), $\partial \bar{\varphi} / \partial z$ is the gridbox mean vertical gradient of some variable $\varphi$, and $K_{\varphi}$ is the eddy diffusivity coefficient for that variable. In the MYJ parameterization used for the CPM experiments, the eddy diffusivity is parameterized as a function of turbulent kinetic energy (TKE), which is predicted with a 1.5-order closure model (Janjić 1994). The implied assumption that all turbulence is subgrid scale contrasts to the LES framework where it is assumed that the largest turbulent eddies are actually not subgrid scale. In the LES framework, an eddy viscosity $\nu$ is calculated as the product of a squared mixing length $l^{2}$, and the magnitude of the grid-resolved strain rate tensor $|\mathbf{S}|$

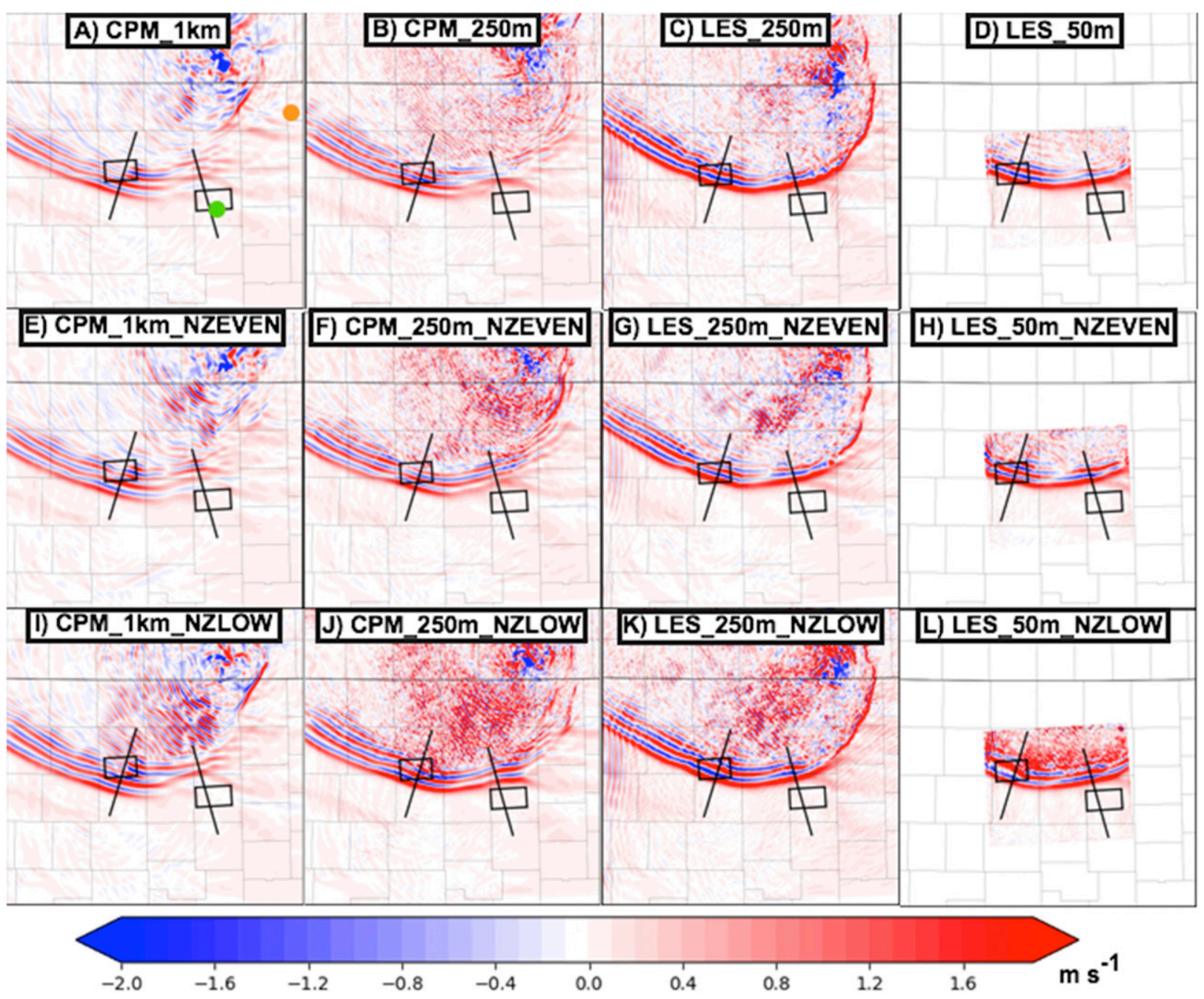

FIG. 6. Vertical velocity $\left(\mathrm{m} \mathrm{s}^{-1}\right)$ at $1 \mathrm{~km} \mathrm{AGL}$ at 0700 UTC $11 \mathrm{Jul}$ for (a)-(d) 50 default vertical levels, (e)-(h) NZEVEN experiments, and (i)-(l) NZLOW experiments. (a),(e),(i) CPM_1km, (b),(f),(j) CPM_250m, (c),(g),(k) LES_250m, and (d),(h),(i) LES_50m. Also shown as black lines are the "west" and "east" cross sections and the box used for averaged vertical profiles shown in subsequent figures. Green and orange dots on (a) are the locations of the CLAMPS and NSSL1 observations, respectively, shown in Fig. 8. 

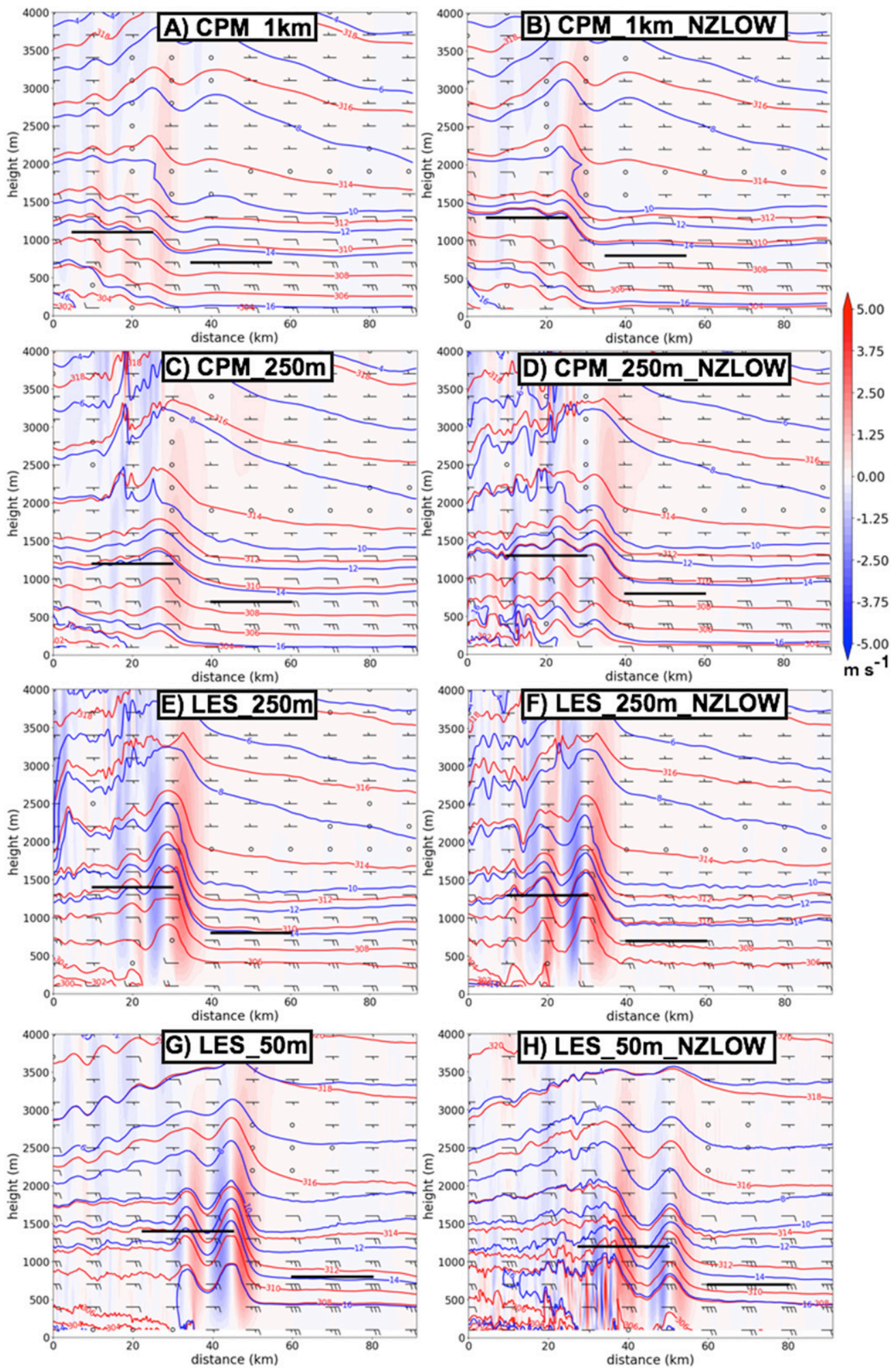

FIG. 7. Vertical velocity (shaded; $\mathrm{m} \mathrm{s}^{-1}$ ), potential temperature (red contours; $\mathrm{K}$ ), and water vapor mixing ratio (blue contours; $\mathrm{g} \mathrm{kg}^{-1}$ ) in east cross sections from Fig. 6 for (a) CPM_1 km, (b) CPM_1km_NZLOW, (c) CPM_250m, (d) CPM_250m_NZLOW, (e) LES_250m, (f) LES_250m_NZLOW, (g) LES_50m, and (h) LES_50m_NZLOW. Barbs show the component of wind parallel to the cross section. 
TABLE 4. Bore amplitudes for simulated bores shown in Figs. 7 and 8. The observed amplitude was 1.39 .

\begin{tabular}{lcc}
\hline \hline \multicolumn{1}{c}{ Experiment } & $\begin{array}{c}\text { West cross-sectional } \\
\text { amplitude }\end{array}$ & $\begin{array}{c}\text { East cross-sectional } \\
\text { amplitude }\end{array}$ \\
\hline CPM_1km & 1.61 & 1.51 \\
CPM_250m & 1.63 & 1.59 \\
LES_250m & 1.76 & 1.74 \\
LES_50m & 1.77 & 1.74 \\
CPM_1km_NZLOW & 1.52 & 1.55 \\
CPM_250m_NZLOW & 1.66 & 1.61 \\
LES_250m_NZLOW & 1.85 & 1.72 \\
LES_50m_NZLOW & 1.63 & 1.63 \\
\hline
\end{tabular}

$$
\nu=l^{2}|\mathbf{S}|=\left(c_{s} \Delta\right)^{2}|\mathbf{S}| .
$$

In Eq. (2), $\Delta$ is the grid spacing, calculated as a geometric average when vertical and horizontal grid spacings are different, and $c_{s}$ is an empirically determined coefficient. A value of $c_{s}=0.17$ was found to work well in Lilly (1967). Our initial tests (not shown) suggested that a value of $c_{s}=0.125$ provides the best balance of resolving the undular bore well without an excessively noisy appearance to the forecast.

The entire suite of experiments described above is run for the 11 July 2015 case (Table 2). Based on the results from these experiments (section 4, below), a limited selection of these experiments is then run for the other cases due to limitations on computational resources (Table 3). The purpose of the other cases is to determine how general the conclusions from the 11 July case study are over a variety of bores.

\section{11 July results}

This section focuses on the 11 July case study to examine the impacts of horizontal and vertical grid spacings on the simulated bore structure and on the upscale impacts of the bore on the convective inhibition (CIN) of the mesoscale environment. The focus is on CIN, rather than convective available potential energy (CAPE), because these convectively generated bores during PECAN tended to occur in environments that already had sufficient CAPE but had further convection limited by the CIN.

\section{a. Bore structure}

The $1 \mathrm{~km}$ AGL vertical velocity at the 4-h lead time of 0700 UTC (Fig. 6) provides a first look at the differences among the simulations. The two black lines on each panel of Fig. 6 are referred to as the "west" and "east" cross sections according to their location on the map. Despite the continuous bore propagating in southwestward, southeastward, and eastward directions seen in the observations (please see Fig. 1a for observation), all three simulations with 1-km horizontal grid spacing have very little signal of the southeastward-propagating bore along the east cross section and almost no sign of the eastward-propagating bore section (Figs. 6a,e,i). Reducing the CPM horizontal grid spacing to $250 \mathrm{~m}$ provides better resolution of the southeastwardpropagating section of the bore (Figs. 6b,f,j), especially in the NZLOW experiment (Fig. 6j), but still very little indication of the eastward propagating section. Remaining at 250-m horizontal grid spacing, but changing from the CPM to LES framework, further improves the southeastward-propagating part of the bore along the east cross section and allows the eastward-propagating section to be properly resolved (Figs. 6c,g,k). Further reducing the horizontal grid spacing to $50 \mathrm{~m}$ has little apparent impact on the bore structure within the 50-m domain (Figs. 6d,h,l), except for the NZLOW experiment (Fig. 6l) as discussed further below. These results suggest that while there is a slight improvement in the bore structure resulting from a decrease of CPM grid spacing from $1 \mathrm{~km}$ to $250 \mathrm{~m}$, it is necessary to switch to the LES framework to fully resolve the expected bore structure. A further reduction of the LES grid spacing to $50 \mathrm{~m}$ has minimal further impact on the bore structure, although this result is limited by the smaller size of the 50-m domain.

The NZEVEN experiments (Figs. 6e,f,g,h) generally appear quite similar to the baseline experiments in Figs. 1a,b,c,d. However, the NZLOW experiments resolve greater continuity between the parts of the bore propagating in the southwestward and southeastward directions in all experiments except for those with $1-\mathrm{km}$ grid spacing (Figs. 6j,k,1). The cross sections through the bore provide further information about the impacts of horizontal and vertical grid spacings on the simulated bore structure (e.g., Fig. 7; please see Figs. 2a and 3 for observation reference). Since the differences among the experiments are qualitatively similar in the east and west cross sections, and since there is little qualitative difference between the NZEVEN and baseline experiments, Fig. 7 focuses on the baseline and NZLOW experiments for the east cross section. The bore-like feature simulated with $1-\mathrm{km}$ horizontal grid spacing (Figs. 7a,b) is too smooth and minimally undular, although it does show the mean layer lifting expected of a bore. The undulations are slightly enhanced in the 250-m CPM simulations (Figs. 7c,d), while they are greatly enhanced in the 250-m LES simulations (Figs. 7e,f). For all 250-m simulations (Figs. 7c-f), the default vertical grid spacing results in most of the vertical velocity being confined to the leading edge of the bore while NZLOW results in 

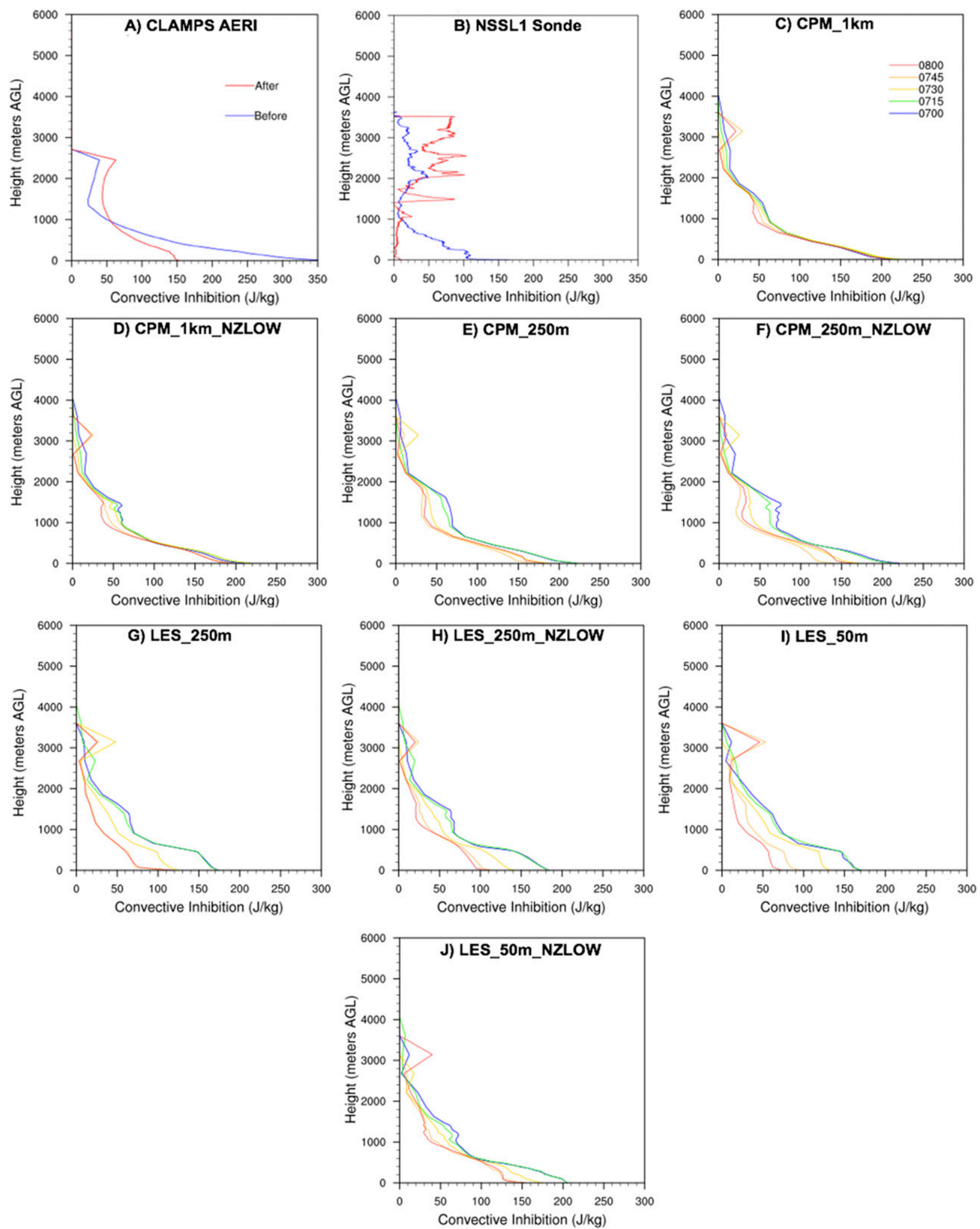

FIG. 8. Time evolution of convective inhibition (CIN; horizontal axis) as a function of height (vertical axis). (a),(b) CIN retrieved from CLAMPS AERI (green dot in Fig. 6a) and NSSL1 mobile soundings (orange dot in Fig. 6a), respectively. Model CIN profiles are averaged over the central box of the east cross sections from Fig. 6 at 15-min intervals from 0700 UTC (blue) to 0800 UTC (red) in the (c) CPM_1km, (d) CPM_1km_NZLOW, (e) CPM_250m, (f) CPM_250m_NZLOW, (g) LES_250m, (h) LES_250m_NZLOW, (i) LES_50m, and (j) LES_50m_NZLOW experiments. 

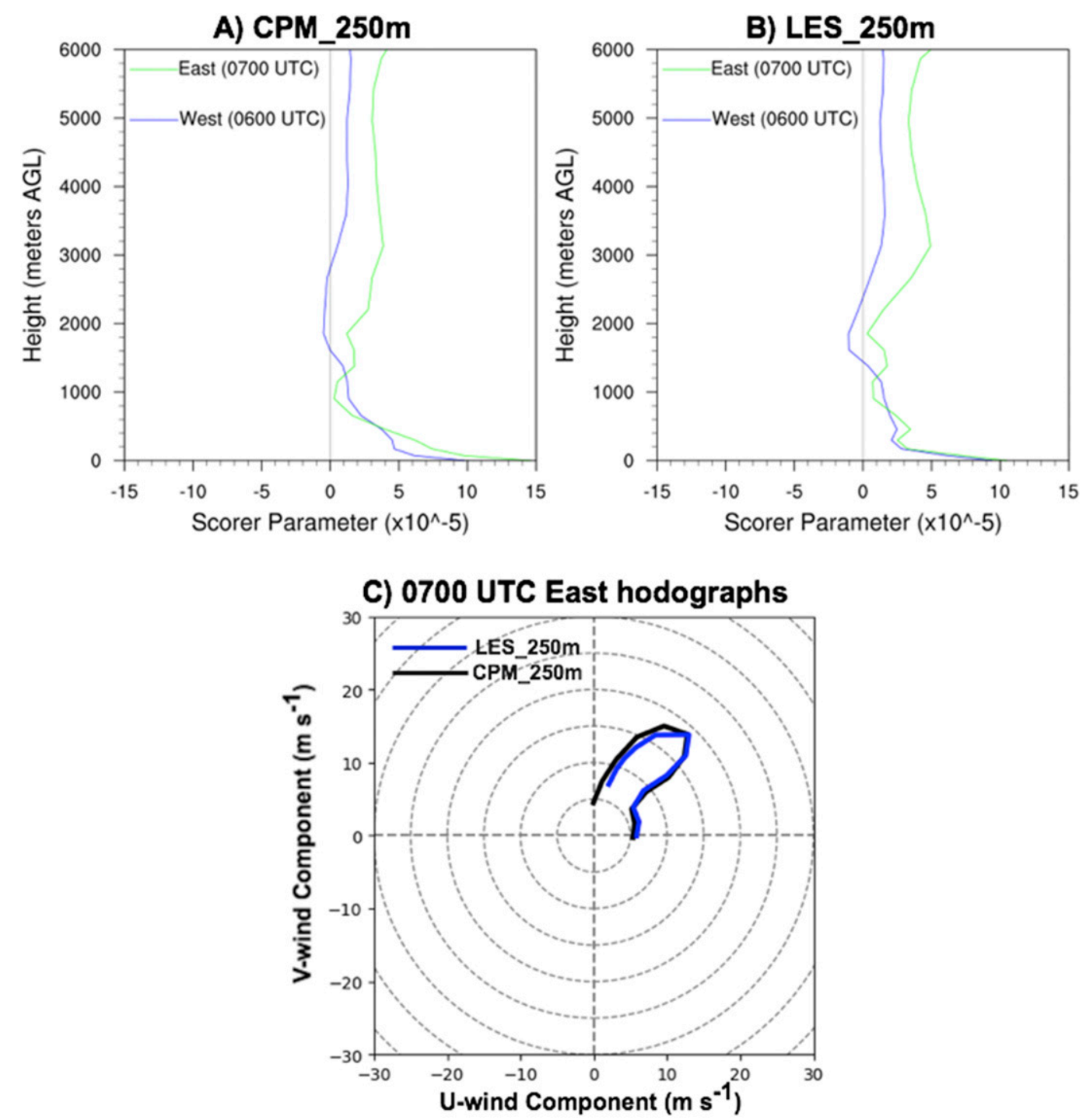

FIG. 9. Vertical profile of Scorer parameter at 0600 and 0700 UTC in the central box of the west (blue) and east (green) cross sections, respectively, for the (a) CPM_250m and (b) LES_250m experiments. (c) 0-5-km hodographs corresponding to the green lines in (a) for the CPM_250m (black hodograph) and in (b) for LES_250m (blue hodograph) experiments.

multiple undulations of similar amplitude. Further reduction of horizontal grid spacing to $50 \mathrm{~m}$ (Figs. 7g,h) causes the bore to propagate a little farther along the cross section by this time. Otherwise there is only a slight change in structure with the default vertical levels, but with NZLOW the structure looks markedly different. The LES_50m_NZLOW simulation shows a transition from smooth undulations to rapid vertical velocity fluctuations, indicative of resolved turbulence, after about 1.5 wavelengths of undulation. This is qualitatively very similar to the observations (Fig. 3), but not necessarily improving on the active subgrid-scale parameterized turbulence that occurs in this region at coarser resolutions (e.g., Johnson et al. 2018).

The horizontal thick black lines in Fig. 7 denote the prebore and postbore depth of the strongly stable nocturnal boundary layer ( $h_{0}$ and $h_{1}$, respectively), calculated following Johnson et al. (2018). In short, the method assumes that potential temperature is conserved during bore passage. The postbore height of each prebore parcel is calculated as the height where the same potential temperature as in the prebore parcel is found. The prebore parcel that experiences the maximum lifting is taken to be at $h_{0}$. While the assumption of conserved potential temperature is clearly violated for 


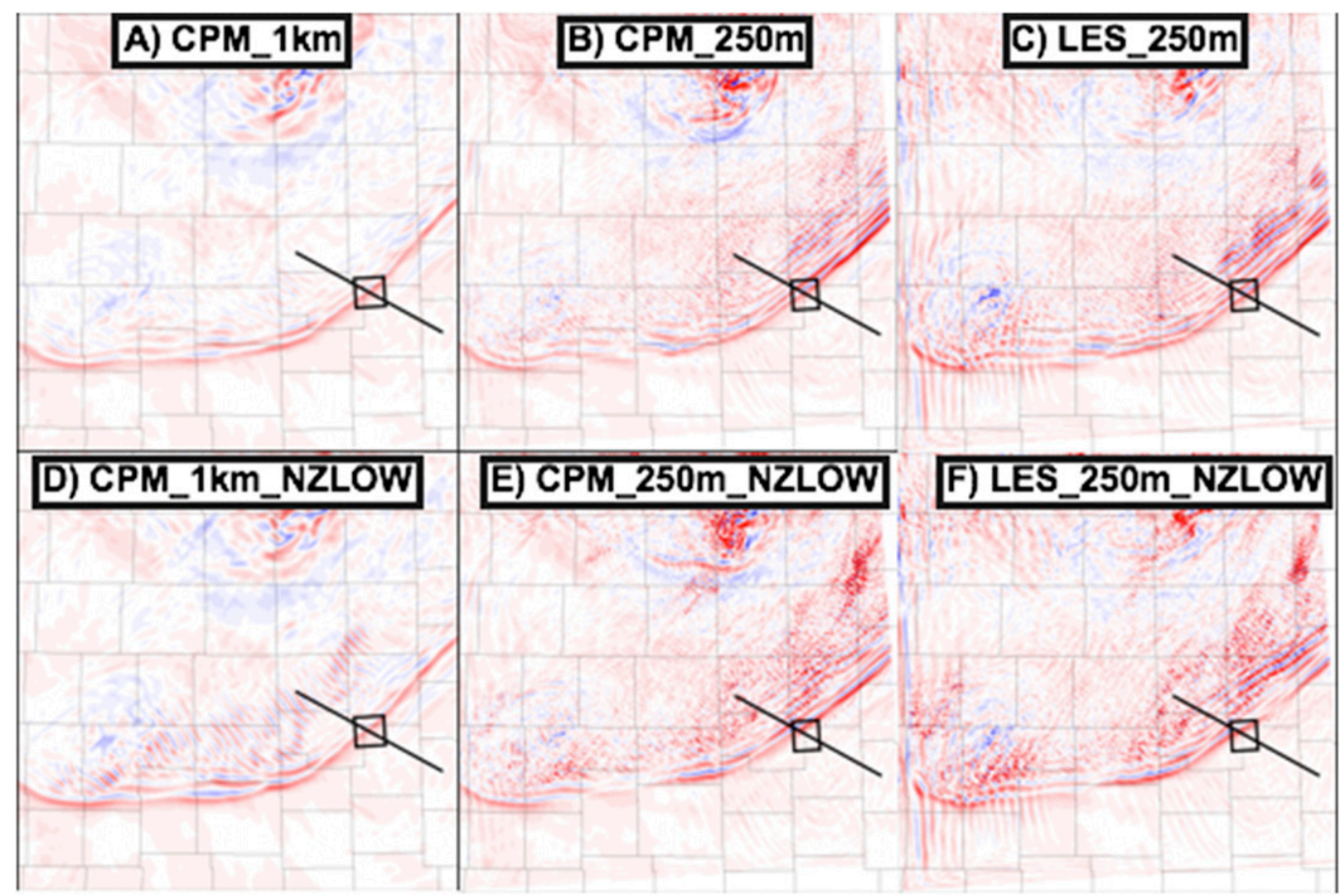

FIG. 10. As in Fig. 6, but for the 7 Jun 2015 bore.

turbulent bores (i.e., amplitude greater than $\sim 4$; Rottman and Simpson 1989), the bores considered in this study are not strong enough to be dominated by turbulence. However, there may still be a small amount of mixing that should be kept in mind when interpreting the results (Johnson et al. 2018).

The ratio $h_{1} / h_{0}$ provides the bore amplitudes summarized in Table 4 for comparison to the observed amplitude of 1.4. All experiments show a larger bore amplitude than observed, suggesting a model bias that is unrelated to the horizontal and vertical grid configurations considered in this study. In fact, the simulations in the LES framework actually have slightly more high-biased amplitudes in Table 4 than the CPM simulations. We speculate that the amplitude bias could be caused by errors in the microphysical parameterization (e.g., Johnson et al. 2018) or errors in the model initial conditions. Such errors would be expected to influence the cold pool depth or the Froude number of the ambient flow, which are the two parameters that determine bore amplitude in theory (Rottman and Simpson 1989).

\section{b. Upscale impacts}

While it is of interest to resolve the bores that influence nocturnal convection as well as possible, it is perhaps even more important to resolve their upscale influences on the larger-scale environment that subsequent convection may occur in. Bores influence their environment primarily through mean layer lifting and vertical turbulent mixing (Koch et al. 2008a). This can modify the environmental CIN, preconditioning the atmosphere for subsequent convection (Parsons et al. 2019). The best estimate of the true impacts of the bore on environmental CIN for this case are obtained from the CLAMPS AERI retrievals before (blue) and after (red) bore passage, as well as an immediate pre and postbore sonde launched by the NSSL1 mobile sonde team during the PECAN IOP (Figs. 8e,j). In general, the observations at the AERI location (green dot, Fig. 6a) and NSSL1 location (orange dot, Fig. 6a) show a clear reduction in CIN for parcels originating below $\sim 1 \mathrm{~km}$ at the AERI location (Fig. 8e), and a nearly complete erosion of CIN below $\sim 1 \mathrm{~km}$ at the NSSL1 location (Fig. $8 \mathrm{j}$ ) as a result of bore passage.

The simulated CIN is calculated using a profile averaged over the black boxes in the east cross section of Fig. 6 to remove small-scale fluctuations at 15 -min increments during bore passage. The simulations with $1-\mathrm{km}$ grid spacing show very little CIN reduction at low levels (Figs. 8a,f), while the CPM 250-m simulations do show a slight reduction of CIN at low levels (Figs. 8b,g). The LES 250-m simulations show a much 

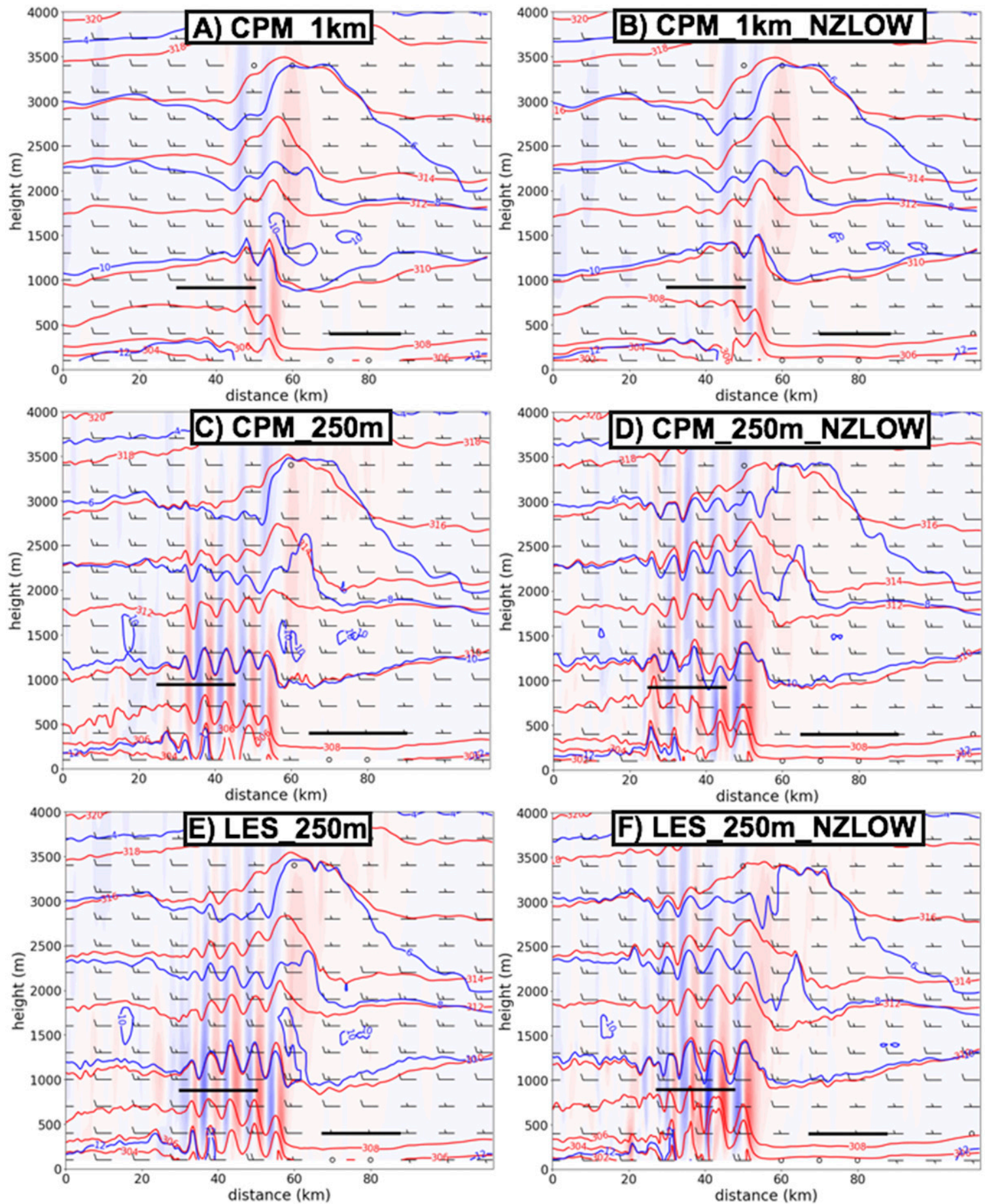

FIG. 11. As in Fig. 7, but for the 7 Jun 2015 bore.

more pronounced low-level CIN reduction than all CPM simulations (Figs. 8c,h). The impacts on lowlevel CIN are changed much less by the change from LES $250 \mathrm{~m}$ to LES $50 \mathrm{~m}$ (Figs. 8d,i) than from the change to CPM $250 \mathrm{~m}$ to LES $250 \mathrm{~m}$. Very similar results are obtained in the west cross sections of Fig. 6 (not shown).

For this case then, it is necessary to both reduce the horizontal grid spacing to $250 \mathrm{~m}$ and select the appropriate turbulence closure model for vertical mixing (i.e., use the 
TABLE 5. As in Table 4, but for the other three cases (7 Jun, 26 Jun, and $2 \mathrm{Jul}$ ).

\begin{tabular}{lccc}
\hline \hline \multicolumn{1}{c}{ Experiment } & $\begin{array}{c}\text { 7 Jun } \\
\text { amplitude }\end{array}$ & $\begin{array}{c}\text { 26 Jun } \\
\text { amplitude }\end{array}$ & $\begin{array}{c}\text { 2 Jul } \\
\text { amplitude }\end{array}$ \\
\hline CPM_1km & 1.66 & 2.20 & 1.61 \\
CPM_250m & 1.75 & 1.63 & 1.44 \\
LES_250m & 1.69 & 1.99 & 1.52 \\
CPM_1km_NZLOW & 1.71 & 3.05 & 1.54 \\
CPM_250m_NZLOW & 1.60 & 1.75 & 1.31 \\
LES_250m_NZLOW & 1.57 & 2.63 & 1.42 \\
\hline
\end{tabular}

LES framework), in order to resolve the reduction of the low-level CIN that characterizes the impact of the bore on the larger-scale environment. Since this conclusion seems to conflict with the increased amplitude bias seen in the LES experiments (Table 4), we speculate that the difference is related to the vertical turbulent mixing rather than the mean layer lifting.

Before turning attention to the other cases, the differences between the bore sensitivity in the southwestward- and southeastward-propagating directions for this case are briefly considered. In particular, we aim to shed light on why the southwestward-propagating section of the bore was qualitatively well resolved in all simulations while the southeastward-propagating section of the bore was much more sensitive to the configuration of the horizontal and vertical grid spacings. Previous studies have shown that the Scorer parameter, which is related to stability and bore-relative wind curvature, minus the squared wavenumber of a potentially trapped wave $\left(k^{2}\right)$ must transition from a positive value at lower levels to a negative value in a higher-altitude layer in order to trap the wave energy at low levels and maintain a quasi-steady-state bore (e.g., Johnson et al. 2018). For a typical bore wavelength of $\sim 10 \mathrm{~km} k^{2}$ is $\sim 10^{-8}$, which is much smaller than typical magnitudes of the Scorer parameter and therefore omitted. Furthermore, partial ducting may occur even for uniformly positive Scorer parameter, provided that the Scorer parameter decreases significantly with height (Scorer 1949; Koch et al. 2008b). Therefore, we use the Scorer parameter as a qualitative guide of where ducting may be occurring when it is approaching zero or negative values. The Scorer parameter averaged over the east (green lines in Fig. 9) and west (blue lines in Fig. 9) black box in Fig. 6 is shown in Fig. 9 for the CPM 250-m (Fig. 9a) and the LES 250-m (Fig. 9b) experiments. The profiles are taken just before the bore enters the box in order to reflect the environment actually experienced by the
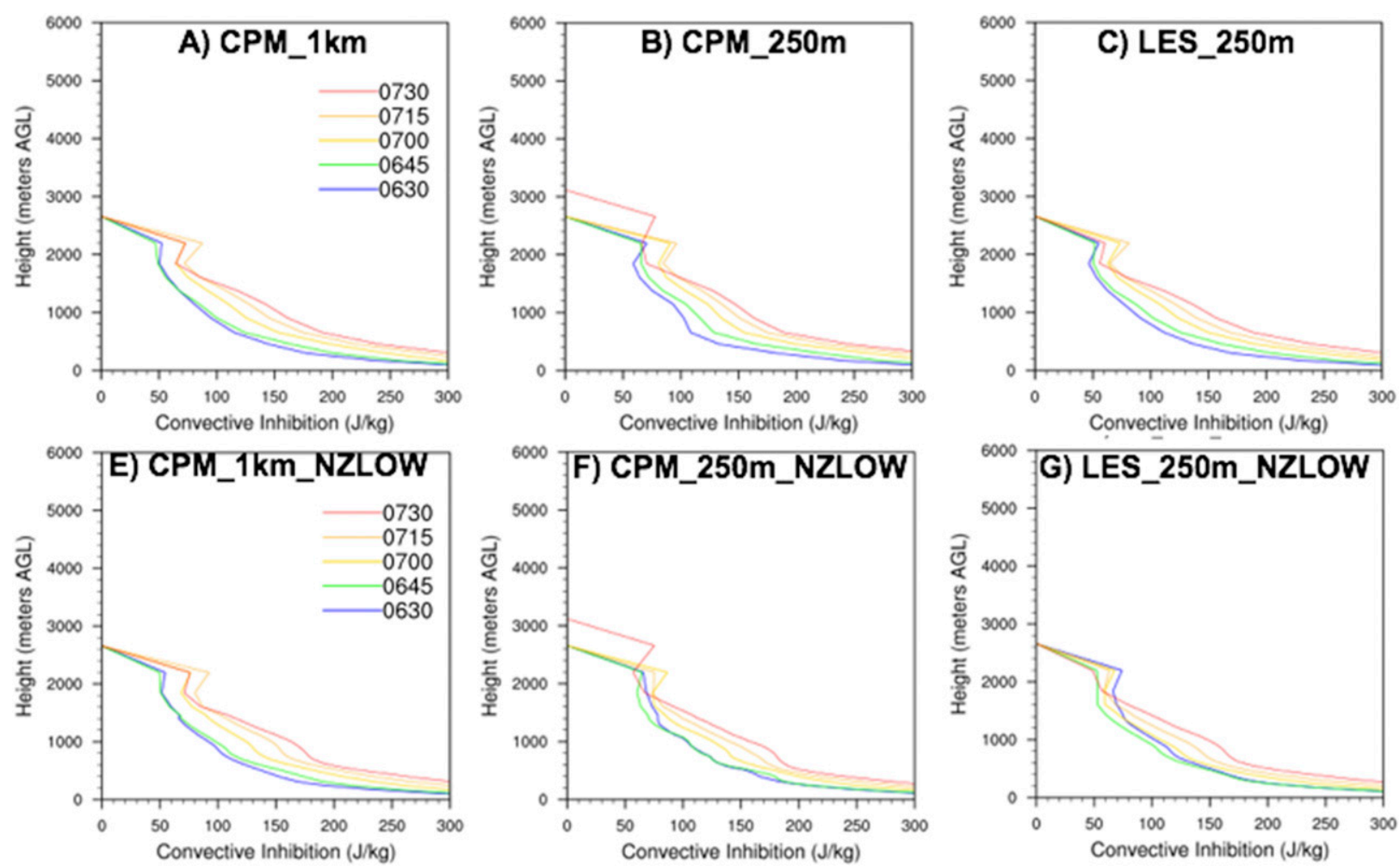

FIG. 12. As in Fig. 8, but for the 7 Jun 2015 bore. 

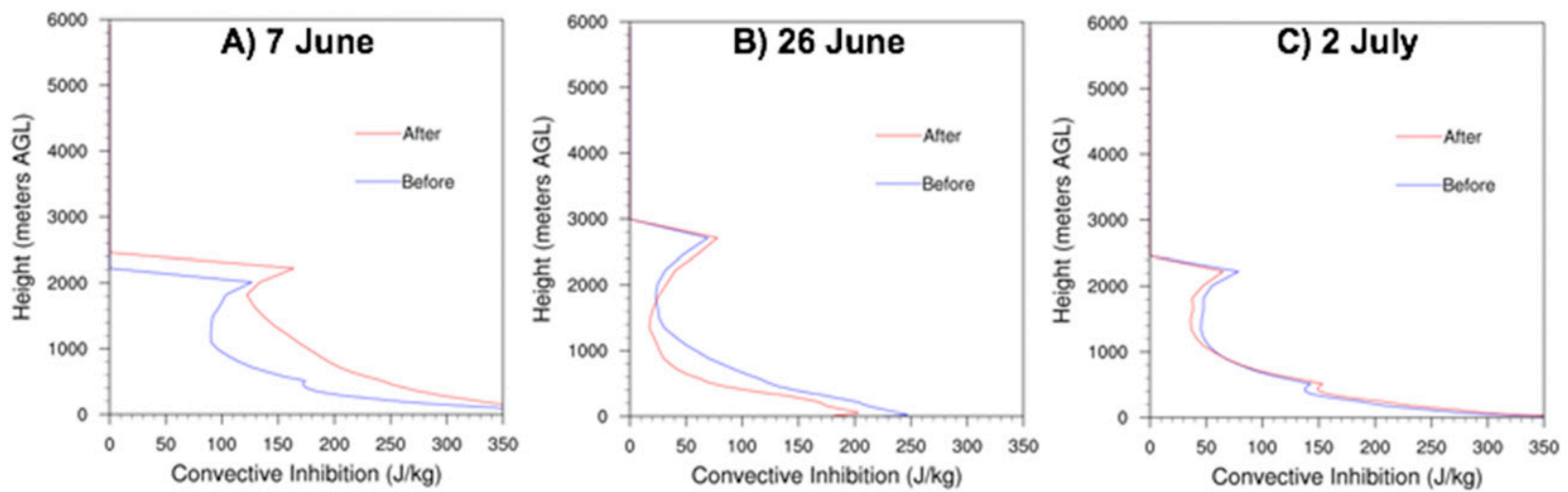

FIG. 13. As in Fig. 8e, but for calculations from (a) FP3 AERI data for the 7 Jun bore, (b) FP3 AERI data for the 26 Jun bore, and (c) MP1 CLAMPS AERI data for the 2 Jul bore.

bore, which corresponds to 0600 UTC for the green lines and 0700 UTC for the blue lines. In the CPM 250-m experiment the Scorer parameter becomes negative at $\sim 1600-2600 \mathrm{~m}$ AGL for the southwestwardpropagating section of the bore (blue line in Fig. 9a), creating a wave duct to trap the bore energy beneath it. For the southeastward-propagating section of the bore there is no corresponding wave duct (green line in Fig. 9a) except for a near-zero Scorer parameter at $\sim 900 \mathrm{~m}$ (Fig. 9a). However, since this is near $\mathrm{h}_{0}$ and well below $\mathrm{h}_{1}$ (Fig. 2) it is at too low an altitude to trap wave energy. In the LES 250-m experiment the Scorer parameter does become nearly zero at $\sim 1800 \mathrm{~m}$ ahead of the southeastward-propagating section of the bore (green line in Fig. 9b), likely creating at least a partial wave duct. The cause of this difference can be seen by comparing the wind hodograph corresponding to the green lines in Figs. 9a and 9b (Fig. 9c). The LES 250-m hodograph (Fig. 9c; blue) shows sharper curvature than the CPM 250-m hodograph (Fig. 9c; black) indicating a shallower low-level jet (LLJ) in the LES experiment. Therefore, we can conclude

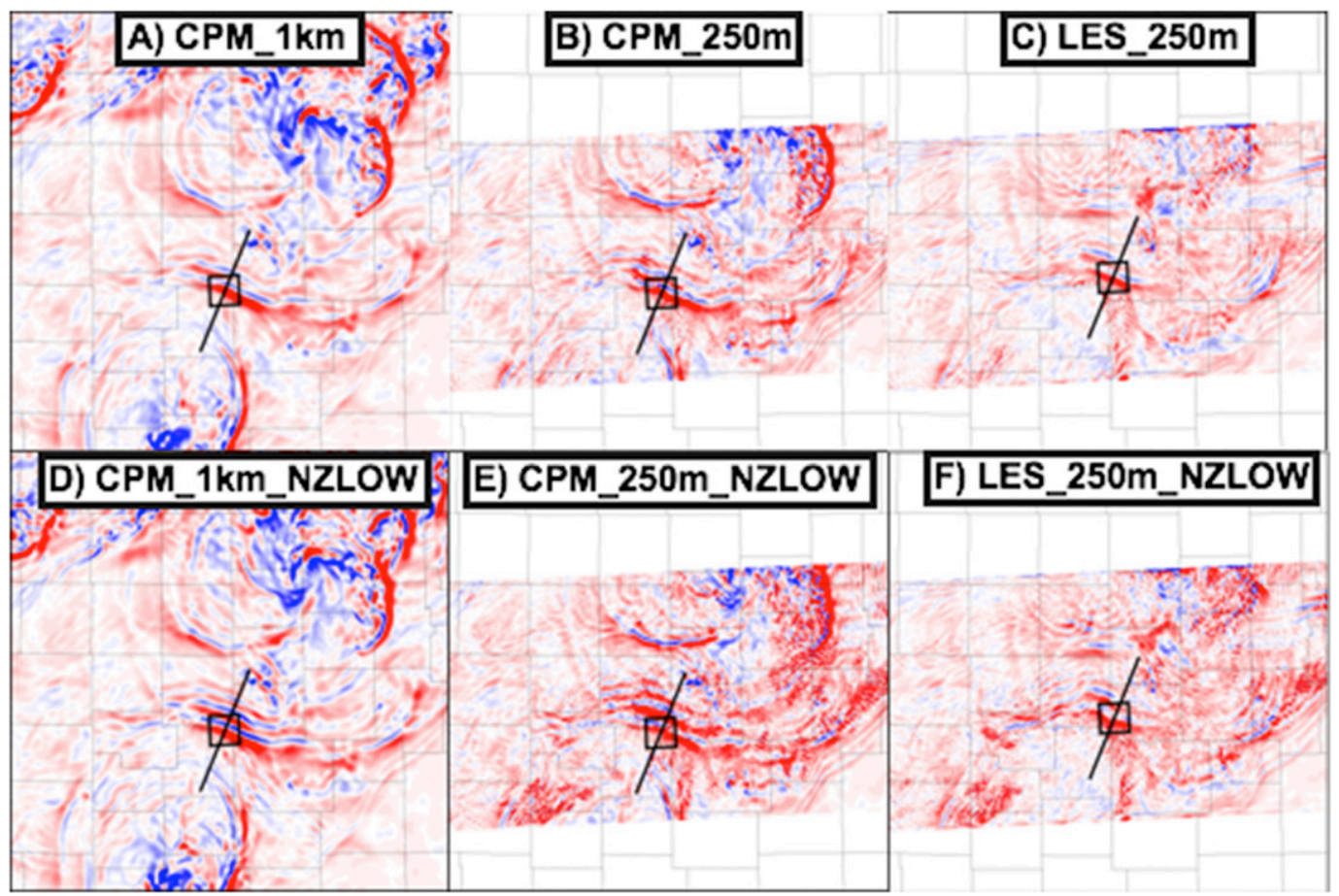

FIG. 14. As in Fig. 6, but for the 26 Jun 2015 bore. 

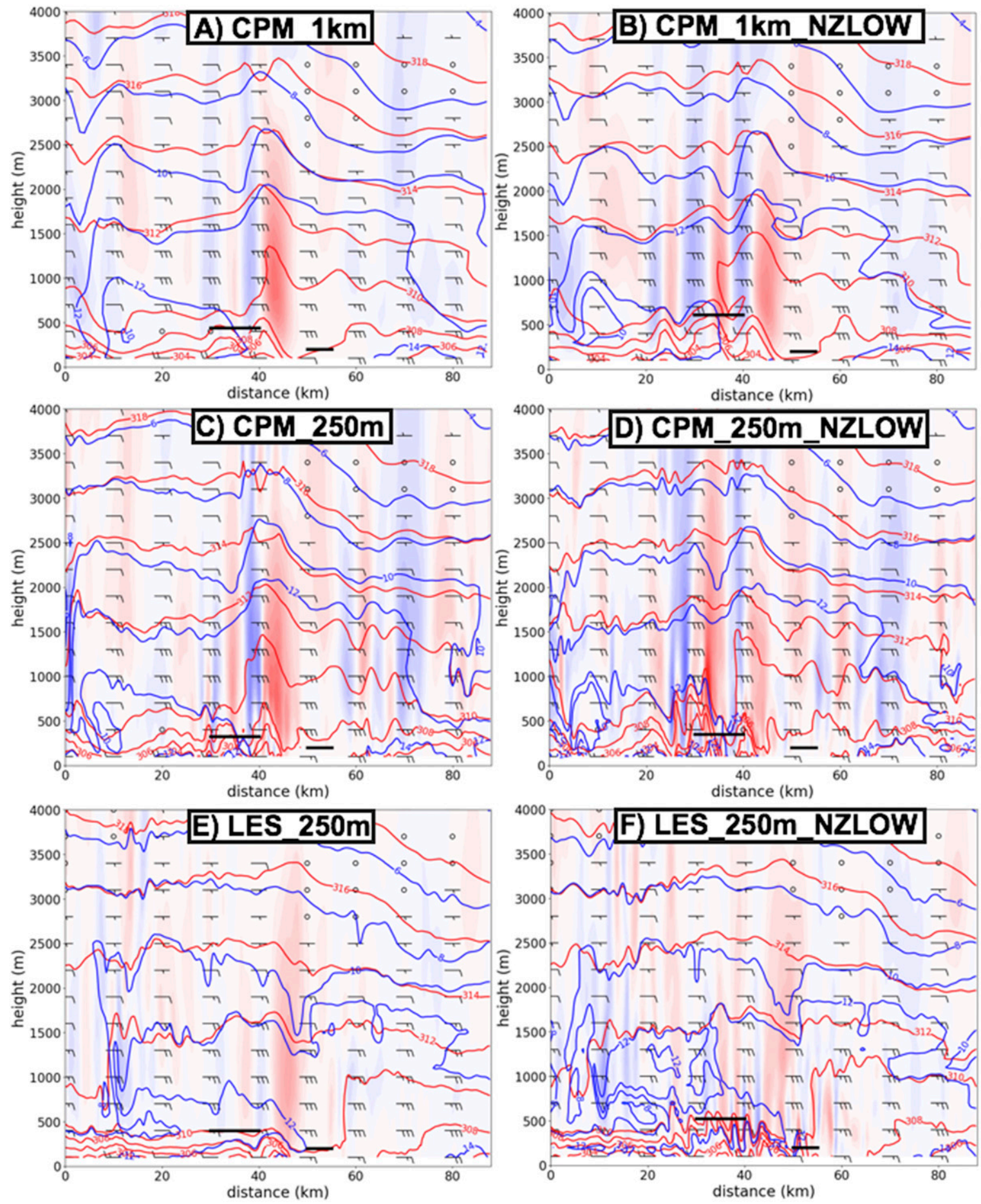

FIG. 15. As in Fig. 7, but for the 26 Jun 2015 bore.

that in this case, even the relatively crudely resolved LLJ in the experiments with coarser horizontal and vertical grid spacing is able to support a southwestward-propagating bore, while the more finely resolved LLJ in the LES experiments is needed to support a southeastward-propagating bore. It is likely that this difference works in conjunction with the differences in vertical turbulent mixing inferred above to create the sensitivities described in this section. 

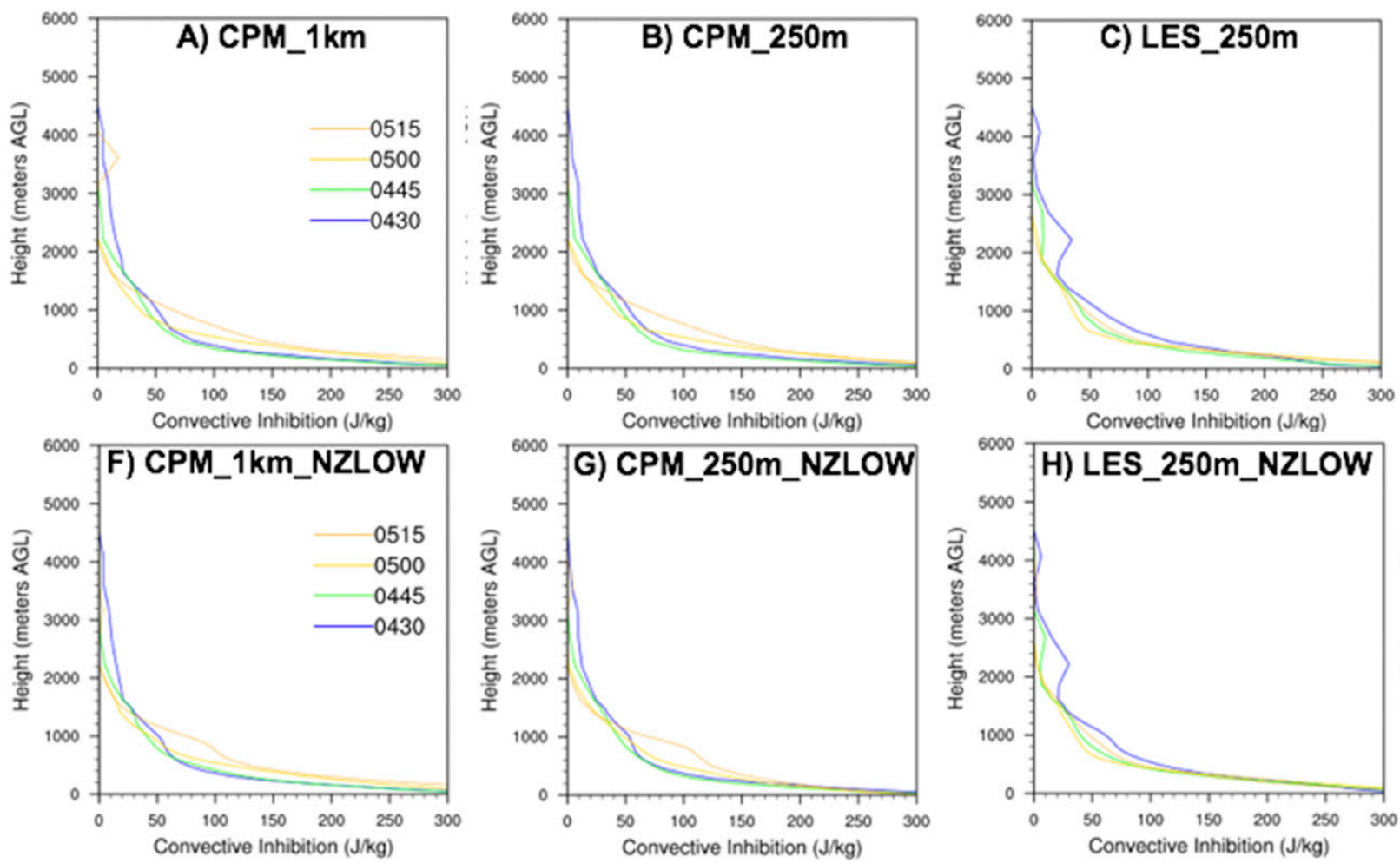

FIG. 16. As in Fig. 8, but for the 26 Jun 2015 bore.

\section{Other cases}

In this section, three additional cases are similarly evaluated in order to determine whether the results in section 4 are unique to that one case or more generally applicable. Since there was little impact of NZEVEN and the 50-m grid spacing experiments, these most computationally expensive simulations are omitted in this section. The experiments considered in this section are given in Table 3 .

\section{a. 7 June 2015}

The $1 \mathrm{~km}$ AGL vertical velocity plots valid at 0700 UTC 7 June 2015 are shown in Fig. 10. The main qualitative difference among these experiments is that the experiments with 250-m horizontal grid spacing (Figs. 10b,c,e,f) resolve more undulations in the bore than the experiments with 1-km grid spacing (Figs. 10a,d). The corresponding vertical cross sections (Fig. 11) show that there are only subtle differences in the bore structure beyond the more pronounced undulations in the bores with 250-m horizontal grid spacing (Figs. 11c-f). Unlike the 11 July case, where all simulations have a too large bore amplitude, the bore amplitude for all simulations in this case (Table 5) is much less than the observed amplitude of 2.76 . However, the differences among the simulations are much smaller than the difference from the observations. One reason for the low bias in bore amplitude for this case may be that the model bores are evaluated at 0700 UTC, while the observed bore amplitude is only available at 0430 UTC. While the average simulated amplitude is a closer fit to the observations at the observation time (not shown), the differences among the experiments are qualitatively similar throughout the forecast period. Therefore, as described above in section 3, we focus on the common 4-h lead time and find that the sensitivity to horizontal and vertical grid spacings at this lead time for this case is less than for the 11 July case. The conclusion that the sensitivity of the simulated bore to these horizontal and vertical grid spacings is small for this case is further supported by the similarly increasing CIN in all experiments (Fig. 12), which is also consistent with the observations (Fig. 13a). The increase, rather than decrease, of CIN resulting from the bore passage in this case is consistent with the absence of a strong vertical moisture gradient in this case (Fig. 11). For example, in the 11 July case water vapor in the ambient environment generally decreases from $\sim 15 \mathrm{~g} \mathrm{~kg}^{-1}$ at $500 \mathrm{~m}$ to $\sim 10 \mathrm{~g} \mathrm{~kg}^{-1}$ at $1500 \mathrm{~m}$ (Fig. 7), while in the 7 June case water vapor only decreases from $\sim 11 \mathrm{~g} \mathrm{~kg}^{-1}$ 


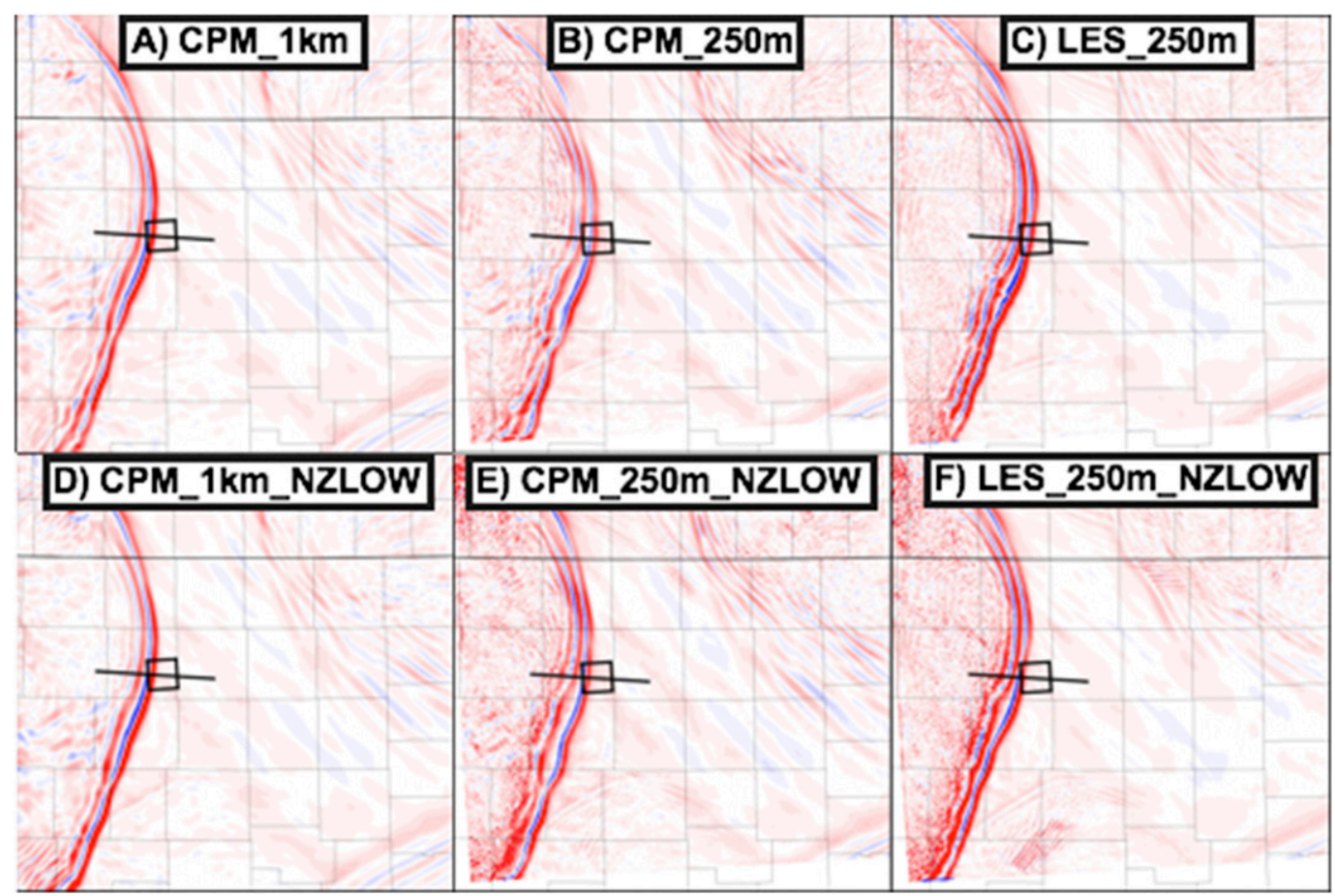

FIG. 17. As in Fig. 6, but for the 2 Jul 2015 bore.

at $500 \mathrm{~m}$ to $\sim 10 \mathrm{~g} \mathrm{~kg}^{-1}$ at $1500 \mathrm{~m}$ (Fig. 11). Lifting a layer of air causes adiabatic cooling, which all else equal, would be expected to increase CIN of parcels lifted from that layer by making them less buoyant than parcels lifted from that altitude prior to the bore lifting. Note that this is different than the adiabatic destabilization expected within the lifted layer, and is only an approximation since much of the atmospheric column can experience (relatively small) lifting as well. If the lifted layer also transports higher moisture from below, then the parcel lifted from that layer also does not need to be lifted as far before reaching its lifting condensation level and warming diabatically compared to parcels lifted from that altitude prior to the bore lifting. In this case the lack of a significant vertical moisture gradient allows the adiabatic cooling caused by lifting to dominate the potential lofting/mixing of moisture that also affects CIN.

\section{b. 26 June 2015}

Unlike the other cases in this study, the 26 June bore is evaluated at the 2-h forecast lead time (i.e., 0500 UTC) instead of the 4-h lead time. Indications of the cold pool to the south of the bore, which the simulated bores interact with shortly after $\sim 0530$ UTC, can be seen in both Fig. 14 and 15. Figure 14 also shows the relatively complex and convectively disturbed environment that this bore occurs within. While this somewhat complicates the analysis, it is also the type of case where it is most important to properly simulate the bores because of the high probability that the bores will interact with subsequent convection. Similar to the 11 July case study, the bore structure is relatively similar between the 1-km and 250-m CPM simulations (Figs. 15a,c) but quite different between the 250-m CPM and LES simulations (Figs. 15c,e). The experiments with enhanced vertical grid spacing (Figs. 15b,d,f) generally have undulations that are less smooth and less laminar, and therefore likely more turbulent, in comparison to the experiments with default vertical levels (Figs. 15a,c,e). In terms of the impact of the bore on the mesoscale environment experienced by subsequent convection, the CPM simulations have an increase in CIN below about $1200 \mathrm{~m}$ AGL resulting from bore passage (Figs. 16a,b,f,g). However, the 250-m LES simulations (Fig. 16c,h) show a reduction of CIN at $\sim 400-1400 \mathrm{~m}$ AGL that is similar to the reduction of CIN below $\sim 1500 \mathrm{~m}$ in the observations resulting from bore passage (Fig. 13b). The improved resolution of how the bore impacts the environment in the LES experiments is not well reflected by the impact on the bore amplitude (Table 5), suggesting that the CIN profile may be a more relevant method of evaluating the upscale impacts of NWP bore simulations.

\section{c. 2 July 2015}

Similar to the 11 July case, decreased horizontal grid spacing and the LES framework both increase the 

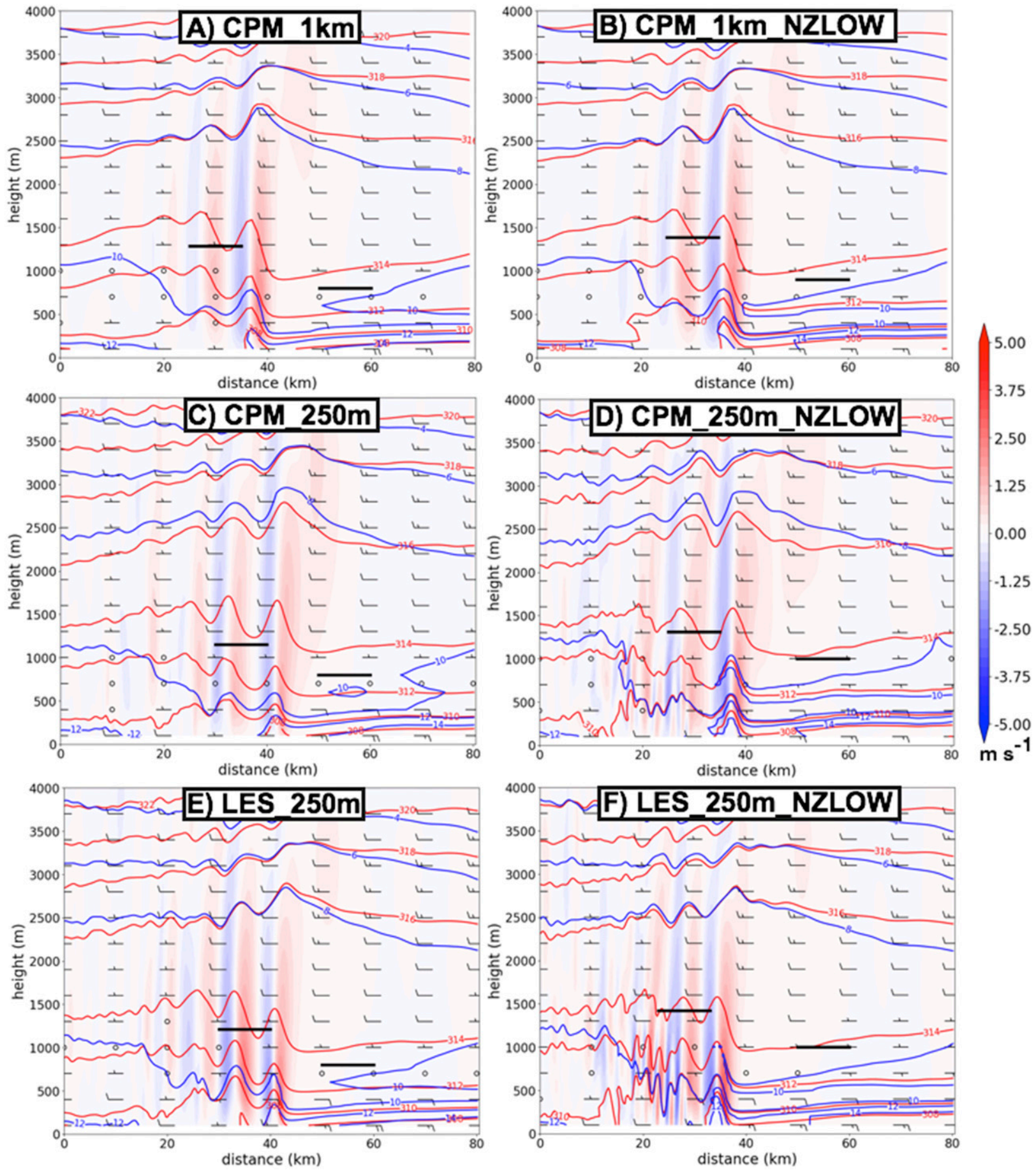

FIG. 18. As in Fig. 7, but for the 2 Jul 2015 bore.

number of resolved bore undulations and the overall along-bore continuity (Figs. 17a,b,c), while the increased number of vertical levels results in a more turbulent appearance behind the first couple of wave fronts at 250-m grid spacing (Figs. 17e,f). Figure 18 also shows the more turbulent appearance behind the leading wave front for both 250-m experiments with NZLOW (Figs. 18d,f), compared to the default vertical grid spacing (Figs. 18c,e). All simulated bores in this case result in a reduction in CIN below $\sim 500 \mathrm{~m}$ AGL (Fig. 19). There is an increase in CIN at $\sim 500-1700 \mathrm{~m}$ AGL, although at $250-\mathrm{m}$ grid spacing this increase is 

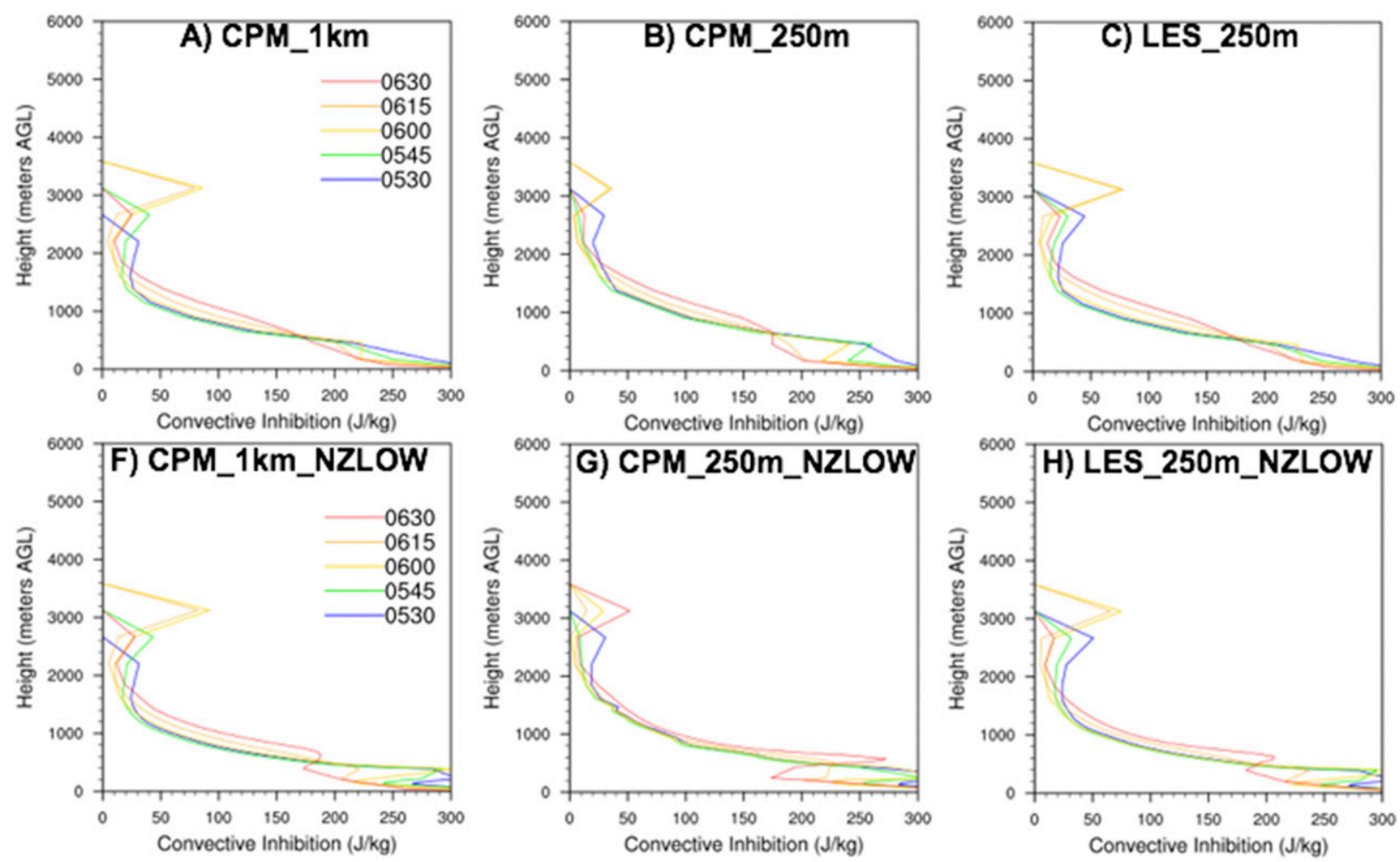

FIG. 19. As in Fig. 8, but for the 2 Jul 2015 bore.

reduced with NZLOW (Figs. 19g,h), in comparison to the default vertical levels (Figs. 19b,c). Above $\sim 1800 \mathrm{~m}$, there is a reduction in CIN in all experiments (Fig. 19). The CIN reduction below $\sim 500 \mathrm{~m}$ was not seen in the observations (Fig. 13c). This difference from observations is likely the result of the prebore CIN being too high in this layer in all simulations. The main difference among the experiments is that the increased CIN at $\sim 500-1700 \mathrm{~m}$ is much less, and more consistent with observations (Fig. 13c), in both 250 -m grid spacing experiments when using NZLOW (Figs. 19g,h) rather than the default vertical levels (Figs. 19b,c). Thus, in contrast to the other cases, the low-level vertical resolution was more important for better predicting the upscale impacts of the bore than the difference between the LES and CPM framework at the $250-\mathrm{m}$ horizontal grid spacing.

\section{Summary and conclusions}

It was hypothesized that subkilometer numerical model grid spacing may be needed in cases where a bore plays a dominant role in influencing subsequent convection. As a first step toward fully testing this hypothesis, the present study examines the effect of different horizontal and vertical grid spacings, and the method of parameterizing vertical mixing, on both the structure of simulated bores and on the modification of CIN in the postbore mesoscale environments. Although we have not considered a sufficient number of cases to establish statistical significance, this multicase assessment aims to at least determine which results are consistent across several different bore events.

The experiments for the 11 July case revealed that the qualitative bore structure was improved, compared to observations, by decreasing CPM grid spacing from 1000 to $250 \mathrm{~m}$. Improvements were also obtained by changing from CPM to LES framework at 250-m grid spacing, decreasing the low-level vertical grid spacing, and decreasing LES grid spacing from 250 to $50 \mathrm{~m}$ in the NZLOW experiment. A particularly noteworthy difference was the appearance of the observed eastward-propagating section of the bore in the LES experiments but not the CPM experiments. The observed reduction of low-level CIN resulting from bore passage was also much better simulated by the LES experiments than the CPM experiments. Thus, the greatest impact on improving the simulation of the bore and its upscale impact on the environment for this case resulted from the LES framework. In this framework, no PBL scheme is used to parameterize the vertical 
turbulent mixing. Instead, the Smagorinsky scheme provides the closure model for vertical turbulent mixing.

The dominant influence of the parameterization of turbulent mixing was also found for the 26 June case. However, for the 2 July case the enhanced vertical resolution played a greater role than the turbulent mixing parameterization in improving the upscale impact of the bore on CIN. In the 7 June case, the observed CIN was actually increased during bore passage. This is likely due to lower environmental moisture with a weaker vertical gradient on this case than the others. In such an environment, the adiabatic cooling associated with the bore lifting would have the primary impact on CIN. In this case, all experiments performed similarly.

In summary, reducing horizontal grid spacing to less than $1 \mathrm{~km}$ can improve simulations of bores and the upscale impacts of the bores on the environment experienced by subsequent convection. Changing the closure model for vertical turbulent mixing from a PBL parameterization to the Smagorisky scheme based on LES assumptions can provide further improvements. In some cases enhancing the vertical resolution at low levels can provide further improvements still. However, decreasing the LES grid spacing to $50 \mathrm{~m}$ may not be worth the computational expense. The relative importance of each of these aspects of the subkilometer model configuration can vary from case to case. Further studies with more cases would be needed to better understand under what conditions the horizontal resolution, vertical resolution, or vertical mixing parameterization will be most important. Future work should also focus specifically on the processes of interaction between bores and ongoing or subsequent convection, in addition to the impacts of the bores on the ambient environment that may be experienced by the subsequent convection.

Acknowledgments. The work is primarily supported by NSF Award AGS-1359703. This work used the Extreme Science and Engineering Discovery Environment (XSEDE), which is supported by National Science Foundation Grant ACI-1053575. This work also used the Cheyenne machine at NCAR's Computational and Information Systems Laboratory (CISL), sponsored by NSF. Data were provided by NCAR/EOL under the sponsorship of the National Science Foundation. The various participants and agencies that made the PECAN project possible, and contributed to IOP data collection, are especially appreciated, as well as the wrfhelp@ucar.edu help desk for help with the WRF. vinterp utility. The manuscript was improved by the comments of three anonymous reviewers.

\section{REFERENCES}

Blake, B. T., D. B. Parsons, K. R. Haghi, and S. G. Castleberry, 2017: The structure, evolution, and dynamics of a nocturnal convective system simulated using the WRF-ARW model. Mon. Wea. Rev., 145, 3179-3201, https://doi.org/10.1175/ MWR-D-16-0360.1.

Bryan, G. H., J. C. Wyngaard, and J. M. Fritsch, 2003: Resolution requirements for the simulation of deep moist convection. Mon. Wea. Rev., 131, 2394-2416, https://doi.org/10.1175/15200493(2003)131<2394:RRFTSO > 2.0.CO;2.

Cioni, G., and C. Hohenegger, 2017: Effect of soil moisture on diurnal convection and precipitation in large-eddy simulations. J. Hydrometeor., 18, 1885-1903, https://doi.org/10.1175/ JHM-D-16-0241.1.

Clark, A. J., W. A. Gallus Jr., M. Xue, and F. Kong, 2010a: Growth of spread in convection-allowing and convectionparameterizing ensembles. Wea. Forecasting, 25, 594-612, https://doi.org/10.1175/2009WAF2222318.1.

$\ldots,-\ldots$, and 2010b: Convection-allowing and convection-parameterizing ensemble forecasts of a mesoscale convective vortex and associated severe weather environment. Wea. Forecasting, 25, 1052-1081, https://doi.org/10.1175/ 2010WAF2222390.1.

Coleman, T. A., and K. R. Knupp, 2011: Radiometer and profiler analysis of the effects of a bore and a solitary wave on the stability of the nocturnal boundary layer. Mon. Wea. Rev., 139, 211-223, https://doi.org/10.1175/2010MWR3376.1.

Davis, C. A., K. W. Manning, R. E. Carbone, S. B. Trier, and J. D. Tuttle, 2003: Coherence of warm-season continental rainfall in numerical weather prediction models. Mon. Wea. Rev., 131, 2667-2679, https://doi.org/10.1175/1520-0493(2003)131<2667: COWCRI $>2.0 . \mathrm{CO} ; 2$.

Dudhia, J., 1993: A nonhydrostatic version of the Penn StateNCAR mesoscale model: Validation tests and simulation of an Atlantic cyclone and cold front. Mon. Wea. Rev., 121, 1493-1513, https://doi.org/10.1175/1520-0493(1993)121<1493: ANVOTP $>2.0 . C O ; 2$.

Ek, M. B., K. E. Mitchell, Y. Lin, E. Rogers, P. Grunmann, V. Koren, G. Gayno, and J. D. Tarpley, 2003: Implementation of Noah land surface model advances in the National Centers for Environmental Prediction operational mesoscale Eta model. J. Geophys. Res., 108, 8851, https://doi.org/10.1029/ 2002JD003296.

Fiori, E., A. Parodi, and F. Siccardi, 2010: Turbulence closure parameterization and grid spacing effects in simulated supercell storms. J. Atmos. Sci., 67, 3870-3890, https://doi.org/10.1175/ 2010JAS3359.1.

Geerts, B., and Coauthors, 2017: The 2015 Plains Elevated Convection At Night (PECAN) field project. Bull. Amer. Meteor. Soc., 98, 767-786, https://doi.org/10.1175/BAMS-D-15-00257.1.

Green, B. W., and F. Zhang, 2015: Idealized large-eddy simulations of a tropical cyclone-like boundary layer. J. Atmos. Sci., $\mathbf{7 2}$, 1743-1764, https://doi.org/10.1175/JAS-D-14-0244.1.

Haghi, K. R., D. B. Parsons, and A. Shapiro, 2017: Bores observed during IHOP_2002: The relationship of bores to the nocturnal environment. Mon. Wea. Rev., 145, 3929-3946, https://doi.org/ 10.1175/MWR-D-16-0415.1.

— , and Coauthors, 2019: Bore-ing into nocturnal convection. Bull. Amer. Meteor. Soc., https://doi.org/10.1175/BAMS-D17-0250.1, in press.

Hanley, K. E., R. S. Plant, T. H. M. Stein, R. J. Hogan, J. C. Nicol, H. W. Lean, C. Halliwell, and P. A. Clark, 2015: Mixing-length 
controls on high-resolution simulations of convective storms. Quart. J. Roy. Meteor. Soc., 141, 272-284, https://doi.org/ 10.1002/qj.2356.

Hartung, D. C., J. A. Otkin, J. E. Martin, and D. D. Turner, 2010: The life cycle of an undular bore and its interaction with a shallow, intense cold front. Mon. Wea. Rev., 138, 886-908, https://doi.org/10.1175/2009MWR3028.1.

Heath, N. K., H. E. Fuelberg, S. Tanelli, F. J. Turk, R. Paul Lawson, S. Woods, and S. Freeman, 2017: WRF nested largeeddy simulations of deep convection during SEAC ${ }^{4} \mathrm{RS}$. J. Geophys. Res. Atmos., 122, 3953-3974, https://doi.org/ 10.1002/2016JD025465.

Hong, S.-Y., and J.-O. J. Lim, 2006: The WRF single-moment 6-class microphysics scheme (WSM6). J. Korean Meteor. Soc., 42, 129-151.

Ito, J., S. Hayashi, A. Hashimoto, H. Ohtake, F. Uno, H. Yoshimura, T. Kato, and Y. Yamada, 2017: Stalled improvement in a numerical weather prediction model as horizontal resolution increases to the sub-kilometer scale. SOLA, 13, 151-156.

Iyer, E. R., A. J. Clark, M. Xue, and F. Kong, 2016: A comparison of 36-60-h precipitation forecasts from convection-allowing and convection-parameterizing ensembles. Wea. Forecasting, 31, 647-661, https://doi.org/10.1175/WAF-D-15-0143.1.

Janjić, Z. I., 1994: The step-mountain eta coordinate model: Further developments of the convection, viscous sublayer, and turbulence closure schemes. Mon. Wea. Rev., 122, 927945, https://doi.org/10.1175/1520-0493(1994)122<0927: TSMECM $>2.0 . \mathrm{CO} ; 2$.

Johnson, A., and X. Wang, 2017: Design and implementation of a GSI-based convection-allowing ensemble data assimilation and forecast system for the PECAN field experiment. Part I: Optimal configurations for nocturnal convection prediction using retrospective cases. Wea. Forecasting, 32, 289-315, https://doi.org/10.1175/WAF-D-16-0102.1.

,$- \ldots$ J. R. Carley, L. J. Wicker, and C. Karstens, 2015: A comparison of multi-scale GSI-based EnKF and 3DVar data assimilation using radar and conventional observations for mid-latitude convective-scale precipitation forecasts. Mon. Wea. Rev., 143, 3087-3108, https://doi.org/10.1175/MWR-D14-00345.1.

- —, and S. Degelia, 2017: Design and implementation of a GSI-based convection-allowing ensemble based data assimilation and forecast system for the PECAN field experiment. Part II: Overview and evaluation of real-time system. Wea. Forecasting, 32, 1227-1251, https://doi.org/10.1175/WAF-D16-0201.1.

,,-- K. Haghi, and D. Parsons, 2018: Evaluation of forecasts of a convectively generated bore using an intensively observed case study from PECAN. Mon. Wea. Rev., 146, 3097-3122, https://doi.org/10.1175/MWR-D-18-0059.1.

Karyampudi, V. M., S. E. Koch, C. Chen, J. W. Rottman, and M. L. Kaplan, 1995: The influence of the Rocky Mountains on the 13-14 April 1986 severe weather outbreak. Part II: Evolution of a prefrontal bore and its role in triggering a squall line. Mon. Wea. Rev., 123, 1423-1446, https://doi.org/10.1175/ 1520-0493(1995)123<1423:TIOTRM>2.0.CO;2.

Knupp, K., 2006: Observational analysis of a gust front to bore to solitary wave transition within an evolving nocturnal boundary layer. J. Atmos. Sci., 63, 2016-2035, https://doi.org/10.1175/ JAS3731.1.
— , and R. Wade, 2016: MP2 UAH MIPS Doppler lidar data (version 1.0). UCAR/NCAR Earth Observing Laboratory, accessed 1 July 2017, https://doi.org/10.5065/D66971TQ.

Koch, S. E., P. B. Dorian, R. Ferrare, S. H. Melfi, W. C. Skillman, and D. Whiteman, 1991: Structure of an internal bore and dissipating gravity current as revealed by Raman lidar. Mon. Wea. Rev., 119, 857-887, https://doi.org/10.1175/15200493(1991)119<0857:SOAIBA $>2.0 . C O ; 2$

—, W. Feltz, F. Fabry, M. Pagowski, B. Geerts, K. M. Bedka, D. O. Miller, and J. W. Wilson, 2008a: Turbulent mixing processes in atmospheric bores and solitary waves deduced from profiling systems and numerical simulation. Mon. Wea. Rev., 136, 1373 1400, https://doi.org/10.1175/2007MWR2252.1.

_ C. Flamant, J. W. Wilson, B. M. Gentry, and B. D. Jamison, 2008b: An atmospheric soliton observed with Doppler radar, differential absorption lidar, and a molecular Doppler lidar. J. Atmos. Oceanic Technol., 25, 1267-1287, https://doi.org/ 10.1175/2007JTECHA951.1.

Lilly, D. K., 1967: The representation of small-scale turbulence in numerical simulation experiments. Proc. IBM Scientific Computing Symp. on Environmental Sciences, Yorktown Heights, NY, IBM, 195-209.

Martin, E. R., and R. H. Johnson, 2008: An observational and modeling study of an atmospheric internal bore during NAME 2004. Mon. Wea. Rev., 136, 4150-4167, https://doi.org/10.1175/ 2008MWR2486.1.

Mlawer, E. J., S. J. Taubman, P. D. Brown, M. J. Iacono, and S. A. Clough, 1997: Radiative transfer for inhomogeneous atmospheres: RRTM, a validated correlated-k model for the longwave. J. Geophys. Res., 102, 16 663-16 682, https:// doi.org/10.1029/97JD00237.

Morrison, H., A. Morales, and C. Vellanueva-Birriel, 2015: Concurrent sensitivities of an idealized deep convective storm to parameterization of microphysics, horizontal grid resolution, and environmental static stability. Mon. Wea. Rev., 143, 20822104, https://doi.org/10.1175/MWR-D-14-00271.1.

Osborne, S. R., and A. Lapworth, 2017: Initiation and propagation of an atmospheric bore in a numerical forecast model: A comparison with observations. J. Appl. Meteor. Climatol., 56, 2999-3016, https://doi.org/10.1175/JAMC-D-17-0045.1.

Parker, M., 2008: Response of simulated squall lines to low-level cooling. J. Atmos. Sci., 65, 1323-1341, https://doi.org/10.1175/ 2007JAS2507.1.

Parsons, D. B., K. Haghi, K. Halbert, B. Elmer, and J. Wang, 2019: The potential role of atmospheric bores and gravity waves in the initiation and maintenance of nocturnal convection over the Southern Great Plains. J. Atmos. Sci., 76, 43-68, https://doi.org/10.1175/JAS-D-17-0172.1.

Potvin, C. K., and M. L. Flora, 2015: Sensitivity of idealized supercell simulations to horizontal grid spacing: Implications for Warn-on-Forecast. Mon. Wea. Rev., 143, 2998-3024, https:// doi.org/10.1175/MWR-D-14-00416.1.

Rai, R., L. Berg, B. Kosovic, S. Haupt, J. Mirocha, B. Ennis, and C. Draxl, 2019: Evaluation of the impact of horizontal grid spacing in terra incognita on coupled mesoscale-microscale simulations using the WRF framework. Mon. Wea. Rev., 147, 1007-1027, https://doi.org/10.1175/MWR-D-18-0282.1.

Rottman, J. W., and J. E. Simpson, 1989: The formation of internal bores in the atmosphere: A laboratory model. Quart. J. Roy. Meteor. Soc., 115, 941-963, https://doi.org/10.1002/qj.49711548809.

Scorer, R. S., 1949: Theory of waves in the lee of mountains. Quart. J. Roy. Meteor. Soc., 75, 41-56, https://doi.org/10.1002/ qj. 49707532308 . 
Shin, H. H., and J. Dudhia, 2016: Evaluation of PBL parameterizations in WRF at subkilometer grid spacings: Turbulence statistics in the dry convective boundary layer. Mon. Wea. Rev., 144, 1161-1177, https://doi.org/10.1175/MWR-D-150208.1.

Skamarock, W. C., J. B. Klemp, J. Dudhia, D. O. Gill, D. M. Barker, W. Wang, and J. G. Powers, 2005: A description of the Advanced Research WRF version 2. NCAR Tech. Note NCAR/TN-468+STR, 88 pp., https://doi.org/10.5065/ D6DZ069T.

Smagorinsky, J., 1963: General circulation experiments with the primitive equations: I. The basic experiment. Mon. Wea. Rev., 91, 99-164, https://doi.org/10.1175/1520-0493(1963)091<0099: GCEWTP $>2.3 . C O ; 2$.

Surcel, M., M. Berenguer, and I. Zawadzki, 2010: The diurnal cycle of precipitation from continental radar mosaics and numerical weather prediction models. Part I: Methodology and seasonal comparison. Mon. Wea. Rev., 138, 3084-3106, https://doi.org/ 10.1175/2010MWR3125.1.

Turner, D., 2016: FP3 AERIoe thermodynamic profile retrieval data (version 2.0). UCAR/NCAR Earth Observing Laboratory, accessed 1 July 2018, http://doi.org/10.5065/D6Z31WV0.

—_, 2017: MP1 OU/NSSL CLAMPS AERIoe thermodynamic profile retrieval data (version 1.1). UCAR/NCAR Earth Observing Laboratory, accessed 1 July 2018, https://doi.org/10.5065/ D6VQ312C.
, and U. Löhnert, 2014: Information content and uncertainties in thermodynamic profiles and liquid cloud properties retrieved from the ground-based Atmospheric Emitted Radiance Interferometer (AERI). J. Appl. Meteor. Climatol., 53, 752-771, https://doi.org/10.1175/JAMC-D-13-0126.1.

Verrelle, A., D. Ricard, and C. Lac, 2015: Sensitivity of highresolution idealized simulations of thunderstorms to horizontal resolution and turbulence parameterization. Quart. J. Roy. Meteor. Soc., 141, 433-448, https://doi.org/10.1002/ qj.2363.

Wallace, J. M., 1975: Diurnal variations in precipitation and thunderstorm frequency over the conterminous United States. Mon. Wea. Rev., 103, 406-419, https://doi.org/10.1175/15200493(1975)103<0406:DVIPAT>2.0.CO;2.

Wang, Y., and X. Wang, 2017: Direct assimilation of radar reflectivity without tangent linear and adjoint of the nonlinear observation operator in the GSI-based EnVar system: Methodology and experiment with the 8 May 2003 Oklahoma City tornadic supercell. Mon. Wea. Rev., 145, 1447-1471, https:// doi.org/10.1175/MWR-D-16-0231.1.

Weisman, M. L., C. Davis, W. Wang, K. W. Manning, and J. B. Klemp, 2008: Experiences with 0-36-h explicit convective forecasts with the WRF-ARW model. Wea. Forecasting, 23, 407-437, https://doi.org/10.1175/2007WAF2007005.1.

Wyngaard, J. C., 2004: Toward numerical modeling in the "terra incognita."' J. Atmos. Sci., 61, 1816-1826, https://doi.org/ 10.1175/1520-0469(2004)061<1816:TNMITT>2.0.CO;2. 